Article

\title{
Multi-Alkenylsilsesquioxanes as Comonomers and Active Species Modifiers of Metallocene Catalyst in Copolymerization with Ethylene
}

\author{
Paweł Groch ${ }^{1, *(D)}$, Katarzyna Dziubek ${ }^{1}$, Krystyna Czaja ${ }^{1}$, Katarzyna Mituła ${ }^{2}$ and \\ Beata Dudziec 2,3 \\ 1 Faculty of Chemistry, Opole University, Oleska 48, 45-052 Opole, Poland; \\ katarzyna.dziubek@uni.opole.pl (K.D.); krystyna.czaja@uni.opole.pl (K.C.) \\ 2 Faculty of Chemistry, Adam Mickiewicz University in Poznań, Umultowska 89B, 61-614 Poznań, \\ Poland; katarzyna.mitula@gmail.com (K.M.); beata.dudziec@gmail.com (B.D.) \\ 3 Centre for Advanced Technologies, Adam Mickiewicz University in Poznań, Umultowska 89C, \\ 61-614 Poznań, Poland \\ * Correspondence: pgroch@uni.opole.pl; Tel.: +48-77-452-7146
}

Received: 24 January 2018; Accepted: 22 February 2018; Published: 24 February 2018

\begin{abstract}
The copolymers of ethylene (E) with open-caged iso-butyl-substituted tri-alkenyl-silsesquioxanes (POSS-6-3 and POSS-10-3) and phenyl-substituted tetra-alkenyl-silsesquioxane (POSS-10-4) were synthesized by copolymerization over the ansa-metallocene catalyst. The influence of the kind of silsesquioxane and of the copolymerization conditions on the reaction performance and on the properties of the copolymers was studied. In the case of copolymerization of E/POSS-6-3, the positive comonomer effect was observed, which was associated with the influence of POSS-6-3 on transformation of the bimetallic ion pair to the active catalytic species. Functionality of silsesquioxanes and polymerization parameters affected the polyhedral oligomeric silsesquioxanes (POSS) contents in the copolymers which varied in the range of 1.33-7.43 wt \%. Tri-alkenyl-silsesquioxanes were incorporated into the polymer chain as pendant groups while the tetra-alkenyl-silsesquioxane derivative could act as a cross-linking agent which was proved by the changes in the contents of unsaturated end groups, by the glass transition temperature values, and by the gel contents (up to $81.3 \%$ for E/POSS-10-4). Incorporation of multi-alkenyl-POSS into the polymer chain affected also the melting and crystallization behaviors.
\end{abstract}

Keywords: ethylene; polyhedral oligomeric silsesquioxanes (POSS); copolymerization; metallocene; crosslinking; active site modifier

\section{Introduction}

One of many advantages of polyhedral oligomeric silsesquioxanes (POSS) is their structural diversity. The POSS compounds have various structures of their silicon-oxygen cores as well as various kinds and numbers of substituents attached to them [1,2]. The POSS derivatives may be classified into three groups: mono-functional POSS, di-functional POSS, and multi-functional POSS, depending on the number of the reactive functional substituents. In the case of the (co)polymerization processes with POSS as (co)monomers, those reactions yield (co)polymers with varied architectures. The copolymers with the POSS cages as pendant side groups or end groups of the polymer chains are prepared when mono-functional POSS are used [3-9]. Di-functional POSS derivatives have attracted considerable attention in recent years. Depending on the types of reactive substituents, they have been successfully incorporated into such macromolecules as polyimide [9-11], polysiloxane [12], polyamide [13], polyurethane [14], polysulfone [15], vinylidene-arylene copolymer [16], and polyethylene [17], via the 
step-growth polymerization process [9-11,13-16,18], or as pendant groups and cross-linkage sites through the coordination copolymerization [17].

In the case of the multi-functional POSS comonomers (octa-functional POSS are mostly investigated within that group) the organic-inorganic polymers can be prepared in different ways, depending on the kinds of their reactive groups [19-23]. Generally, multi-functional POSS derivatives behave as nanosized cross-linkers which take part in the formation of polymer networks $[19,21,22]$ or as precursors in the production of amphiphilic materials [23].

The multi-functional POSS derivatives are useful in preparation of (co)polymers with different structural properties. Matějka et al. [22] reported organic-inorganic epoxy networks based on diglycidyl ether of bisphenol A and poly-(oxypropylene)diamine which were reinforced with multi-functional epoxy-POSS (octa-, tetra-, and di-epoxy POSS comonomer). The obtained materials contained POSS as pendant units of the network chains or as network cross-links of various functionality. Matějka and co-workers [21] also reported modified hybrid epoxy-amine networks with mono- or multi-epoxide POSS which were produced via the reactive blending method. The POSS molecules were incorporated into the organic-inorganic networks as pendant units of the network chains or as network junctions. Liu and co-workers [20] reported the possibility of modifying epoxy resins with the use of an incompletely condensed caged POSS with three reactive hydroxyl groups (POSS-triol). The organic-inorganic hybrid polymers were prepared via in situ polymerization of POSS-triol with diglycidyl ether of bisphenol A over aluminum triacetylacetonate. Chen et al. [19] prepared a novel cross-linker, octa[(trimethoxysilyl)ethyl]-POSS, which was introduced into the hydroxyl-terminated polydimethylsiloxane matrix to prepare a series of novel silicone rubbers. The novel POSS cross-linker was found to significantly enhance the thermal stability and mechanical properties of those rubbers. The incompletely condensed and completely condensed POSS tethered with hydrophilic poly(ethylene glycol) chains were used by Yusa et al. [23] as novel organic-inorganic amphiphilic block molecules in order to obtain self-assembly nanomaterials. To the best of our knowledge, however, there are no reports available of ethylene copolymerization with multi-alkenylsilsesquioxane comonomers over the organometallic catalysts.

Tri- and tetra-alkenyl-silsesquioxane comonomers were used in the present work for copolymerization with ethylene over the metallocene catalyst. The research involved iso-butyl-substituted tri-alkenyl-silsesquioxanes (POSS-6-3 and POSS-10-3) and phenyl-substituted tetra-alkenyl-silsesquioxane (POSS-10-4), which contained the incompletely condensed silicon-oxygen $\mathrm{T}_{4} \mathrm{D}_{3}$ and $\mathrm{M}_{4} \mathrm{~T}_{8}$ cages, respectively (Figure 1 ). The POSS compounds also had various lengths of reactive alkenyl substituents in the silicon-oxygen cages (POSS-6-3 and POSS-10-3, Figure 1).

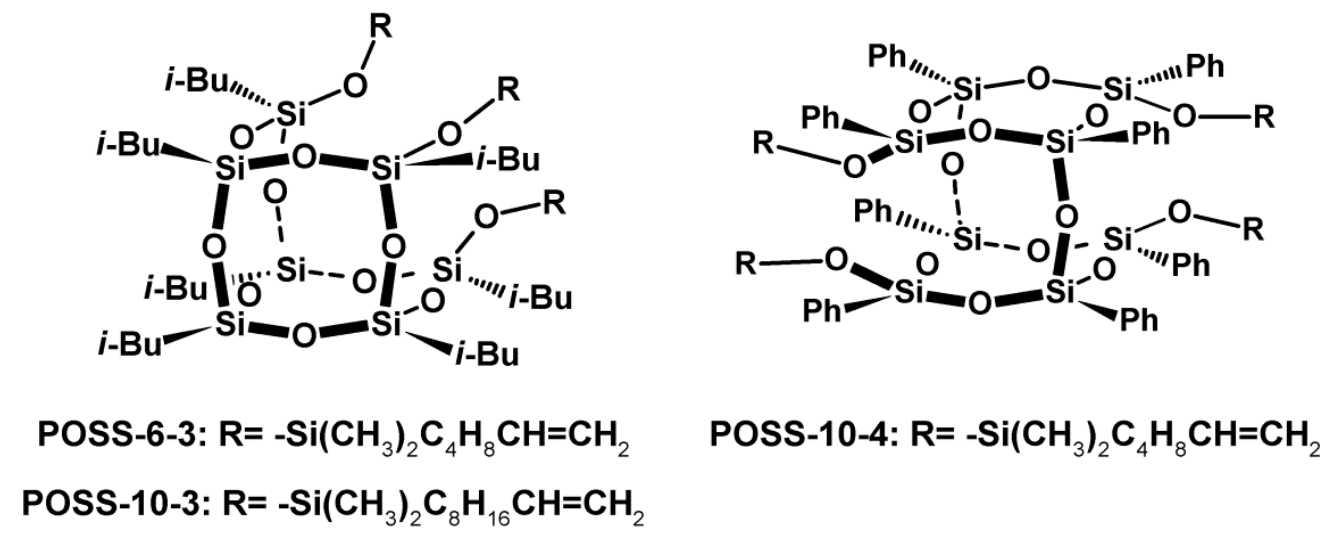

Figure 1. Structures of tri- and tetra-alkenyl-silsesquioxane comonomers.

The rac-ethylenebis(indenyl)zirconium dichloride catalyst $\left(\mathrm{rac}-\mathrm{Et}(\mathrm{Ind})_{2} \mathrm{ZrCl}_{2}\right.$ ) activated by modified methylaluminoxane (MMAO) was applied in the (co)polymerization processes. 
The aim of this work was to study the influence of the kind of POSS as well as of the polymerization conditions, such as concentration of the POSS comonomer in the feed, ethylene pressure, and reaction time, on the performance of ethylene/POSS copolymerization and on the structures and properties of the obtained copolymers. The copolymers were characterized by the following methods: nuclear magnetic resonance $\left({ }^{1} \mathrm{H}\right.$ and $\left.{ }^{13} \mathrm{C} N M R\right)$, Fourier transform infrared spectroscopy (FT-IR), differential scanning calorimetry (DSC), and gel permeation chromatography (GPC). The influence of POSS on the catalytic system activated by MMAO was investigated by ${ }^{1} \mathrm{H}$ NMR. Based on the obtained results, the compositions and structural properties of copolymers were comprehensively analyzed and discussed. We also paid attention to thermal properties of copolymers, including their melting and crystallization behaviors.

\section{Materials and Methods}

\subsection{Materials}

Toluene was purchased from Chempur (Piekary Ślaskie, Poland) and it was refluxed over sodium and distilled under nitrogen prior to use. Modified methylaluminoxane (MMAO, $7 \mathrm{wt} \%$ in toluene, Sigma-Aldrich, Saint Louis, MO, USA), rac-ethylenebis-(1- $\eta^{5}$-indenyl)-zirconium dichloride ( $r a c-E t(I n d){ }_{2} \mathrm{ZrCl}_{2}$, Sigma-Aldrich, Saint Louis, MO, USA), 1,2-dichlorobenzene-d4 (Deutero $\mathrm{GmbH}$, Kastellaun, Germany), hydrochloric acid (35-38\%, Chempur, Piekary Ślaskie, Poland), 2,2'-metylenebis(4-methyl-6-tert-butylfenol) (Sigma-Aldrich, Saint Louis, MO, USA), and methanol (Chempur, Piekary Śląskie, Poland) were used as purchased. Toluene-d8 (Deutero GmbH, Kastellaun, Germany) was dried over molecular sieves ( $4 \AA$ ) and degassed in vacuo, and then it was stored and handled in vacuo.

Ethylene (Grade 3.5, Air Liquide, Kraków, Poland) and nitrogen (Messer, Chorzów, Poland) were used after passing them through a column with the sodium metal supported on $\mathrm{Al}_{2} \mathrm{O}_{3}$. 1,2,4-Trichlorobenzene (TCB, $99 \mathrm{wt} \%$, Aldrich, Saint Louis, MO, USA) was purified by distillation.

\subsection{Experimental Section for the Synthesis of Trialkenyl- and Tetraalkenyl-Substituted Silsesquioxanes}

Tri(alkenyl)-substituted silsesquioxanes derived from cubic-type open-cage trisilanol and tetra(dec-9-enyl)-substituted double-decker silsesquioxanes were synthesized via hydrolytic condensation of incompletely condensed trisilanolisobutyl POSS $\left(i-\mathrm{Bu}_{7}\left(\mathrm{Si}_{7} \mathrm{O}_{9}\right)(3 \mathrm{OH})\right)$ and tetrasilanol silsesquioxane (DDSQ-4OH) with respective chlorosilanes. The obtained products made precursors for hydrosilylation. The procedures were based on the general methodology for alkenyl-substituted silsesquioxanes [24-26]. The compounds were synthesized in the Centre for Advanced Technologies, AMU (Poznań, Poland).

$i$-BuPOSS-3(OMe $2 \mathrm{Si}-\mathrm{Hex}$ ) (Figure 1, POSS-6-3) was produced via hydrolytic condensation of $i-\mathrm{Bu}_{7}\left(\mathrm{Si}_{7} \mathrm{O}_{9}\right)(3 \mathrm{OH})$ with chloro(dimethyl)(hex-5-enyl)silane and it was obtained with the yield of $65 \%$.

${ }^{1} \mathbf{H}$ NMR $\left(300.2 \mathrm{MHz}, \mathrm{CDCl}_{3}, \delta, \mathrm{ppm}\right): 0.11\left(\mathrm{~s}, 18 \mathrm{H},-\mathrm{SiCH}_{3}\right), 0.52-0.62\left(\mathrm{~m}, 20 \mathrm{H},-\mathrm{CH}_{2}-(\right.$ hex-5-enyl), $\left.-\mathrm{CH}_{2}-(\mathrm{i}-\mathrm{Bu})\right), 0.95-0.97\left(\mathrm{~m}, 42 \mathrm{H},-\mathrm{CH}_{3}(\mathrm{i}-\mathrm{Bu})\right), 1.37-1.43\left(\mathrm{~m}, 12 \mathrm{H},-\mathrm{CH}_{2}-\right.$ (hex-5-enyl)), $1.79-1.88(\mathrm{~m}, 7 \mathrm{H}$, $-\mathrm{CH}-(\mathrm{i}-\mathrm{Bu})), 2.01-2.07\left(\mathrm{~m}, 6 \mathrm{H},-\mathrm{CH}_{2}-(\right.$ hex-5-enyl $\left.)\right), 4.91-5.02\left(\mathrm{~m}, 6 \mathrm{H}, \mathbf{H}_{2} \mathrm{C}=\mathrm{CH}-\right), 5.74-5.88(\mathrm{~m}, 3 \mathrm{H}$, $\left.\mathrm{H}_{2} \mathrm{C}=\mathrm{CH}-\right) .{ }^{13} \mathrm{C}$ NMR (100.6 MHz, $\left.\mathrm{CDCl}_{3}, \delta, \mathrm{ppm}\right): 0.47\left(\mathrm{CH}_{3} \mathrm{Si}-\right), 18.14\left(-\mathrm{CH}_{2}-\right), 22.91\left(-\mathrm{CH}_{2}-\right), 23.94$ (i-Bu), 24.14-24.25 (i-Bu), 26.02-26.19 (i-Bu), $32.86\left(-\mathrm{CH}_{2}-\right), 33.77\left(-\mathrm{CH}_{2}-\right), 114.19\left(\mathrm{H}_{2} \mathrm{C}=\mathrm{CH}-\right), 139.33$

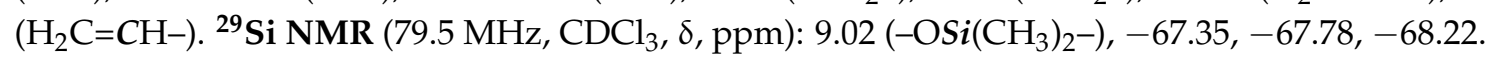

$i$-BuPOSS-3(OMe ${ }_{2} \mathrm{Si}-\mathrm{Dec}$ ) (Figure 1, POSS-10-3) was produced via hydrolytic condensation of $i-\mathrm{Bu}_{7}\left(\mathrm{Si}_{7} \mathrm{O}_{9}\right)(3 \mathrm{OH})$ with chlorodimethylsilane. The product of this process, i.e., tri(hydrodimethylsilyl)-substituted silsesquioxane, was used for hydrosilylation with 1,9-decadiene to give $i$-BuPOSS-3(OMe $2 \mathrm{Si}-\mathrm{Dec})$. The final product was obtained with the yield of $73 \%$.

${ }^{1} \mathrm{H}$ NMR $\left(300.2 \mathrm{MHz}, \mathrm{CDCl}_{3}, \delta, \mathrm{ppm}\right): 0.11\left(\mathrm{~s}, 18 \mathrm{H},-\mathrm{SiCH}_{3}\right), 0.54-40.56\left(\mathrm{~m}, 20 \mathrm{H},-\mathrm{CH}_{2}-\right.$ (dec-9-enyl), $\left.-\mathrm{CH}_{2}-(\mathrm{i}-\mathrm{Bu})\right), 0.95-0.97\left(\mathrm{~m}, 42 \mathrm{H},-\mathrm{CH}_{3}(\mathrm{i}-\mathrm{Bu})\right), 1.28\left(\mathrm{~m}, 36 \mathrm{H},-\mathrm{CH}_{2}-(\right.$ dec-9-enyl)), 1.83-1.86 $(\mathrm{m}, 7 \mathrm{H},-\mathrm{CH}-(i-\mathrm{Bu})), 2.01-2.07\left(\mathrm{~m}, 6 \mathrm{H},-\mathrm{CH}_{2}-(\mathrm{dec}-9-\mathrm{enyl})\right), 4.91-5.02\left(\mathrm{~m}, 6 \mathrm{H}, \mathbf{H}_{2} \mathrm{C}=\mathrm{CH}-\right), 5.75-5.88$ 
$\left(\mathrm{m}, 3 \mathrm{H}, \mathrm{H}_{2} \mathrm{C}=\mathrm{CH}-\right) .{ }^{13} \mathrm{C}$ NMR $\left(100.6 \mathrm{MHz}, \mathrm{CDCl}_{3}, \delta, \mathrm{ppm}\right): 0.48\left(\mathrm{CH}_{3} \mathrm{Si}-\right), 18.32\left(-\mathrm{CH}_{2}-\right), 22.64\left(-\mathrm{CH}_{2}-\right)$ $23.38(i-\mathrm{Bu}), 24.14-24.25(i-\mathrm{Bu}), 26.04-26.20(i-\mathrm{Bu}), 29.15\left(-\mathrm{CH}_{2}-\right), 29.41\left(-\mathrm{CH}_{2}-\right), 29.59\left(-\mathrm{CH}_{2}-\right), 29.68$ $\left(-\mathrm{CH}_{2}-\right), 33.69\left(-\mathrm{CH}_{2}-\right), 34.01\left(-\mathrm{CH}_{2}-\right), 114.23\left(\mathrm{H}_{2} \mathrm{C}=\mathrm{CH}-\right), 139.39\left(\mathrm{H}_{2} \mathrm{C}=\mathrm{CH}-\right) .{ }^{29} \mathrm{Si}$ NMR $(79.5 \mathrm{MHz}$, $\left.\mathrm{CDCl}_{3}, \delta, \mathrm{ppm}\right): 9.10\left(-\mathrm{OSi}\left(\mathrm{CH}_{3}\right)_{2}-\right),-67.36,-67.83,-68.31$.

DDSQ-4OSi-Dec (Figure 1, POSS-10-4) was produced via hydrolytic condensation of DDSQ-4OH with chlorodimethylsilane. The product, i.e., tetra(hydrodimethylsilyl)-substituted double-decker silsesquioxane, was used for hydrosilylation with 1,9-decadiene. The final product was obtained with the yield of $93 \%$ [25].

${ }^{1} \mathbf{H}$ NMR $\left(300 \mathrm{MHz}, \mathrm{CDCl}_{3}, \mathrm{ppm}\right): \delta=0.03\left(\mathrm{~s}, 24 \mathrm{H}, \mathrm{Si}\left(\mathrm{CH}_{3}\right)_{2}-\right), 0.41-0.46\left(\mathrm{~m}, 8 \mathrm{H}, \mathrm{Si}-\mathrm{CH}_{2}-\right)$, 0.95-1.32 (m, 48H, - $\left.\mathrm{CH}_{2}-\right), 1.95-2.03\left(\mathrm{~m}, 8 \mathrm{H},-\mathrm{CH}_{2}-\right), 4.89-4.99\left(\mathrm{~m}, 8 \mathrm{H}, \mathrm{H}_{2} \mathrm{C}=\mathrm{CH}-\right), 5.72-5.85(\mathrm{~m}, 4 \mathrm{H}$, $\left.-\mathrm{CH}=\mathrm{CH}_{2}\right), 7.07-7.44(\mathrm{~m}, 40 \mathrm{H}, \mathrm{Ph}) .{ }^{13} \mathrm{C}$ NMR $\left(101 \mathrm{MHz}, \mathrm{CDCl}_{3}, \mathrm{ppm}\right): \delta=0.14\left(\mathrm{SiCH}_{3}\right), 18.24$ $\left(-\mathrm{H}_{2} C-\right), 23.06\left(-\mathrm{H}_{2} C-\right), 28.97\left(-\mathrm{H}_{2} C-\right), 29.15\left(-\mathrm{H}_{2} C-\right), 29.37\left(-\mathrm{H}_{2} C-\right), 29.44\left(-\mathrm{H}_{2} C-\right), 33.40\left(-\mathrm{H}_{2} C-\right)$, $33.84\left(-\mathrm{H}_{2} \mathrm{C}-\right), 114.06\left(\mathrm{H}_{2} \mathrm{C}=\mathrm{CH}-\right), 127.34-127.73(\mathrm{Ph}), 129.64-130.02(\mathrm{Ph}), 131.78(\mathrm{Ph}), 133.66(\mathrm{Ph})$, 134.10-134.38 (Ph), $139.27\left(\mathrm{H}_{2} \mathrm{C}=\mathrm{CH}-\right) .{ }^{29} \mathrm{Si} \mathrm{NMR}\left(79.5 \mathrm{MHz}, \mathrm{CDCl}_{3}, \mathrm{ppm}\right): \delta=11.01\left(-\mathrm{Si}(\mathrm{Me})_{2}-\right)$, $-76.15,-78.77(-S i-P h-)$.

\subsection{Procedure for Ethylene Homopolymerization and Copolymerization of Ethylene with POSS}

The ethylene polymerization and ethylene/POSS copolymerization processes were carried out in a $500 \mathrm{~cm}^{3}$ glass reactor equipped with a propeller-like mechanical stirrer and a temperature probe. In the case of homopolymerization, the reactor was charged with $150 \mathrm{~cm}^{3}$ toluene and the required volume of the MMAO solution in toluene $\left(\mathrm{n}_{\mathrm{Al}}=3.01 \times 10^{-3} \mathrm{~mol}\right)$. As regards copolymerization experiments, the following ingredients were used: $140 \mathrm{~cm}^{3}$ toluene, MMAO solution in toluene $\left(\mathrm{n}_{\mathrm{Al}}=3.01 \times 10^{-3} \mathrm{~mol}\right)$, and POSS solution in $10 \mathrm{~cm}^{3}$ toluene $([\mathrm{POSS}]=0.67$; $1.67 ; 3.33 ; 6.67 \cdot 10^{-3} \mathrm{~mol} / \mathrm{dm}^{3}$ in the reaction feed). In the next step, the solution of a metallocene catalyst in toluene $\left(\mathrm{n}_{\mathrm{Zr}}=3.5 \cdot 10^{-7} \mathrm{~mol}\right)$ was introduced. Then, the reactor content was heated up to $50{ }^{\circ} \mathrm{C}$ and ethylene $(0.2$ or $0.5 \mathrm{MPa})$ was fed into the reaction system. The ethylene pressure and (co)polymerization temperature were maintained constant during the run. In order to terminate the polymerization process, the $5 \% \mathrm{HCl}$ solution in methanol was introduced into the reaction feed. The obtained polymeric products were filtered and purified by stirring for $2 \mathrm{~h}$ with hexane (in the case of ethylene/POSS copolymers), with the $5 \% \mathrm{HCl}$ solution in methanol, then with methanol, and then they were dried in an oven at $40{ }^{\circ} \mathrm{C}$ for $8 \mathrm{~h}$.

\subsection{Analysis of (Co)polymer, Comonomer, and Catalytic System}

${ }^{1} \mathrm{H},{ }^{13} \mathrm{C}$, and ${ }^{29} \mathrm{Si}$ Nuclear Magnetic Resonance (NMR) analyses for POSS were performed on the Bruker UltraShield 400 and $300 \mathrm{MHz}$ spectrometers (Bruker BioSpin GmbH, Rheinstetten, Germany), using $\mathrm{CDCl}_{3}$ as a solvent. The chemical shifts are reported in ppm with reference to the residual solvent $\left(\mathrm{CHCl}_{3}\right)$ peaks for ${ }^{1} \mathrm{H}$ and ${ }^{13} \mathrm{C}$ and to TMS for ${ }^{29} \mathrm{Si}$.

The ${ }^{1} \mathrm{H}$ and ${ }^{13} \mathrm{C}$ NMR spectra for copolymers were recorded on the UltraShield Bruker spectrometer (400 MHz) (Bruker BioSpin $\mathrm{GmbH}$, Rheinstetten, Germany) at $120{ }^{\circ} \mathrm{C}$ in 1,2-dichlorobenzene-d4 as a solvent. The ${ }^{1} \mathrm{H}$ NMR spectra for the catalytic system were recorded on the same spectrometer $(400 \mathrm{MHz})$ at $20^{\circ} \mathrm{C}$ in toluene-d 8 as a solvent, in $5 \mathrm{~mm}$ cylindrical glass sample tubes. All the experiments were carried out in sealed, high-vacuum systems to avoid any undesired contact with atmospheric air.

The FT-IR spectra were acquired on the Nicolet Nexus 2002 FT-IR spectrometer (Thermo Fisher Scientific, San Jose, CA, USA). The (co)polymer samples were prepared in the form of tablets which were made of the polymer powder and $\mathrm{KBr}$, and their scans were taken in the range from 4000 to $400 \mathrm{~cm}^{-1}$ with the resolution of $2 \mathrm{~cm}^{-1}$. The relative POSS comonomer contents were calculated based on the ratio of the absorption band for the Si-O bond in the POSS units and the internal standard of PE. The unsaturated end groups, vinyl and trisubstituted vinylene, and their relative contents, were 
estimated from the peak intensities at 910 and $840-790 \mathrm{~cm}^{-1}$, respectively, which were normalized using the peak at $2020 \mathrm{~cm}^{-1}$.

The average molecular weights $\left(M_{\mathrm{w}}\right)$ and molecular weight distributions $\left(M_{\mathrm{w}} / M_{\mathrm{n}}\right)$ were found in 1,2,4-trichlorobenzene as a solvent, at $135^{\circ} \mathrm{C}$, at the flow rate of $1 \mathrm{~cm}^{3} / \mathrm{min}$, on the Alliance 135 GPCV 2000 apparatus (Waters, Milford, MA, USA). The data were analyzed using the polystyrene calibration curves.

The melting temperature $\left(T_{\mathrm{m}}\right)$, crystallization temperature $\left(T_{\mathrm{c}}\right)$, and crystallinity degree $\left(X_{\mathrm{c}}\right)$ were measured on the DSC1 calorimeter from Mettler Toledo (Columbus, OH, USA), in closed aluminum pans, under $\mathrm{N}_{2}$. The (co)polymer sample $(10 \mathrm{mg})$ was weighed and then heated up to $170{ }^{\circ} \mathrm{C}$ at the rate of $10^{\circ} \mathrm{C} / \mathrm{min}$, and it was kept at that temperature for $5 \mathrm{~min}$ to remove its thermal history, and then it was cooled down to $30^{\circ} \mathrm{C}$ at $10^{\circ} \mathrm{C} / \mathrm{min}$, and finally again heated up to $170{ }^{\circ} \mathrm{C}$ at $10{ }^{\circ} \mathrm{C} / \mathrm{min}$. The crystallinity degree in per cent was calculated on the basis of $\Delta H_{\mathrm{f}}$ as $X_{\mathrm{c}}=\Delta H_{\mathrm{f}} \times(100 / 290)$ [27].

The glass transition temperatures $\left(T_{\mathrm{g}}\right)$ of the obtained polyethylene and E/POSS copolymers were studied by the differential scanning calorimetry (DSC) method using the TA Instruments DSC 2920 device (New Castle, DE, USA). All the tests were performed under nitrogen and the rate of $10^{\circ} \mathrm{C} / \mathrm{min}$. The $T_{\mathrm{g}}$ value was determined by the inflection point on the curve.

The gel contents of copolymers were determined by solvent extraction, according to the (Polish) standard PN-EN ISO 10147:2013-06P. The copolymer was extracted with $175 \mathrm{~cm}^{3}$ xylene in a Soxhlet extractor glass system. The copolymer samples (about $0.3 \mathrm{~g}$ ) with an antioxidant $(0.65 \mathrm{~g})$ were extracted for $8 \mathrm{~h}$. After extraction, the samples were dried in vacuum at $140{ }^{\circ} \mathrm{C}$ for $2 \mathrm{~h}$ to constant mass. The gel contents of the copolymer samples were calculated from the following equation: \% gel content $=$ [(weight of the sample after extraction) $/$ (weight of the sample before extraction) $] \times 100 \%$.

\section{Results}

\subsection{Performance of E/POSS Copolymerization}

In the case of ethylene copolymerization with POSS, catalyzed by the $\mathrm{rac}-\mathrm{Et}(\mathrm{Ind})_{2} \mathrm{ZrCl}_{2} / \mathrm{MMAO}$ catalytic system, the concentration of the POSS comonomer in the reaction feed was varied in the range from $6.67 \times 10^{-4}$ to $6.67 \times 10^{-3} \mathrm{~mol} / \mathrm{dm}^{3}$ and the ethylene pressure was 0.2 or $0.5 \mathrm{MPa}$. The results of E/POSS copolymerization are presented in Figure 2.

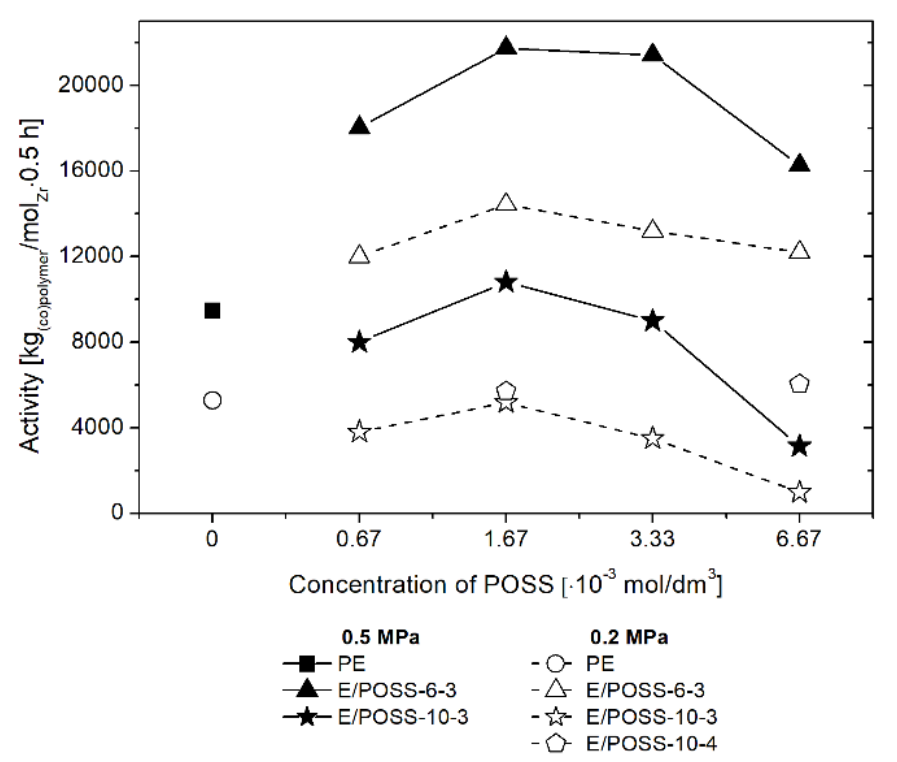

Figure 2. Effect of polyhedral oligomeric silsesquioxanes (POSS) comonomer on performance of ethylene copolymerization with POSS, over the rac-Et(Ind) ${ }_{2} \mathrm{ZrCl}_{2} / \mathrm{MMAO}$ catalytic system. 
The rac-Et(Ind) ${ }_{2} \mathrm{ZrCl}_{2} / \mathrm{MMAO}$ catalytic systems were less active in copolymerization of ethylene with POSS-10-3 and POSS-10-4 in comparison to ethylene homopolymerization (Figure 2) due to the presence of a sterically bulky POSS comonomer in the feed. In contrast, activity of the catalyst was higher for copolymerization of ethylene with the POSS-6-3 comonomer (Figure 2). It should be emphasized that this is the first example of the positive effect of a comonomer in the case of ethylene/POSS copolymerization [3-6,17]. However, a positive effect of comonomers was observed earlier for other organometallic systems, i.e., for both metallocene [28,29] and post-metallocene [30] catalysts, in the case of ethylene copolymerization with $\alpha$-olefins.

The maximum activity of the metallocene catalyst in E/POSS copolymerization occurred at the POSS concentration in the feed of $1.67 \times 10^{-3} \mathrm{~mol} / \mathrm{dm}^{3}$, regardless of the kind of the POSS comonomer and ethylene pressure used (Figure 2). The similar relation was observed in copolymerization of ethylene with the DDSQ comonomer, as reported in our previous work [17]. The increased ethylene pressure led to higher activity of the catalyst (Figure 2).

When the results of the E/POSS-6-3 and E/POSS-10-3 copolymerization processes were compared with each other, it was found that lengthening of the reactive alkenyl substituent at the silicon-oxygen core of the POSS comonomer resulted in decreased catalytic activity (Figure 2). This could be associated with the increased steric hindrance as well as weakened interaction between the open silicon-oxygen cage of POSS-10-3 and the active center of the rac-Et(Ind) ${ }_{2} \mathrm{ZrCl}_{2}$ catalyst. The opposite relation was observed in the case of ethylene copolymerization with monoalkenyl(siloxy)- and monoalkenylsilsesquioxane which contained completely condensed $T_{8}$ cages [6]. However, it should be noted that higher values of catalytic activity were obtained when the tri-alkenylsilsesquioxane comonomers were applied even at a twice lower concentration of the catalyst in the feed (up to $21,740 \mathrm{~kg}$ copolymer $/ \mathrm{mol}_{\mathrm{Zr}} \cdot 0.5 \mathrm{~h}$; Figure 2) in comparison with previously studied monoalkenyl(siloxy)and monoalkenylsilsesquioxanes (3107-13,507 $\mathrm{kg}_{\text {copolymer }} / \mathrm{mol}_{\mathrm{Zr}} \times 0.5 \mathrm{~h}$ ) [6] and the double-decker silsesquioxane derivative $\left(8279-11,490 \mathrm{~kg}_{\text {copolymer }} / \mathrm{mol}_{\mathrm{Zr}} \times 0.5 \mathrm{~h}\right)$ [17].

The effect of the reaction time on the performance of E/POSS copolymerization was also investigated (Figure 3). The activity of the ansa-metallocene/MMAO catalytic system in ethylene homopolymerization sharply decreased as the reaction time was prolonged (Figure 3).
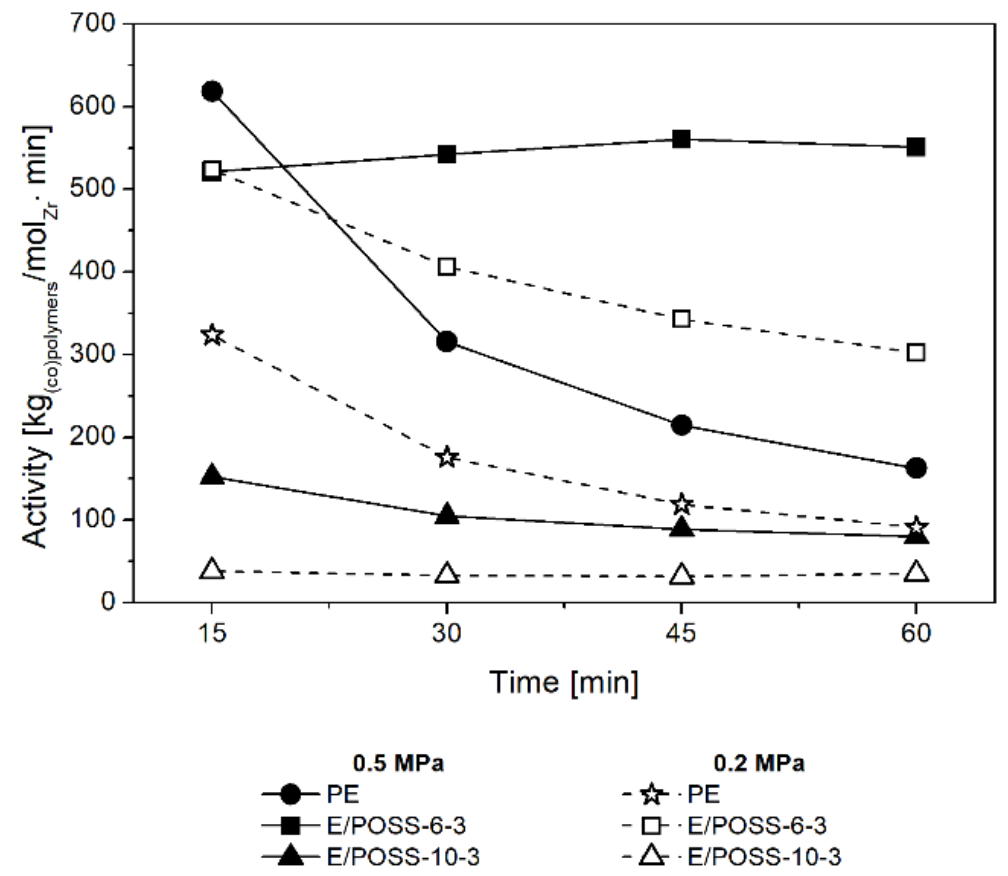

Figure 3. Effect of the reaction time on the activity of the rac-Et(Ind) ${ }_{2} \mathrm{ZrCl}_{2} / \mathrm{MMAO}$ catalytic system in (co)polymerization. 
In the case of ethylene copolymerization with POSS, the catalytic efficiency also decreased with the prolongation of time reaction, regardless of the ethylene pressure, however the changes in activity were less significant. At the same time, however, in the case of ethylene copolymerization with POSS-6-3 at $p_{e}=0.5 \mathrm{MPa}$ and with POSS-10-3 at $p_{e}=0.2 \mathrm{MPa}$, the catalytic activity remained constant despite prolongation of the reaction time. This means that comonomers with incompletely condensed POSS cages do not poison the active center of the ansa-metallocene catalyst. These results indicated high stability of these active species which is attributed to the heterogeneous metallocene catalytic system, what is untypical for homogeneous analogs [31,32].

\subsection{Influence of POSS on Ansa-Metallocene/MMAO Catalytic System}

The NMR spectroscopy was successfully applied to investigate the intermolecular structure of the ionic species relevant to the catalytic homogeneous polymerization [33-42]. These literature data provided important information on the structures of intermediates formed upon the activation of metallocene with MAO in toluene. Nevertheless, the ansa-metallocene catalyst activated by MAO was studied in one case only [36].

In the case of MAO-activated metallocene, the ion pairs $(\mathbf{a}, \mathbf{b}$, and $\mathbf{c})$ were reported on the ${ }^{1} \mathrm{H} N M \mathrm{R}$ analysis based on $\mu$-Me resonance at $-1.3,-0.85$, and $-0.75 \mathrm{ppm}$, respectively. A bimetallic ion pair was observed at a low $\mathrm{Al} / \mathrm{Zr}$ ratio $(<100 \mathrm{~mol} / \mathrm{mol})$ in which case one methyl-group acted as a bridge between $\mathrm{Zr}$ atoms, keeping the Me-MAO- anion in the outer coordination sphere (a) [33,36-38]. In turn, the cationic complexes $\left[\mathrm{Cp}_{2} \mathrm{Zr}(\mu-\mathrm{Me})_{2} \mathrm{AlMe}_{2}\right]^{+} \mathrm{Me}-\mathrm{MAO}^{-}(\mathbf{b})$ and $\mathrm{Cp}_{2} \mathrm{ZrMe}+\leftarrow \mathrm{Me}-\mathrm{Al} \equiv \mathrm{MAO}(\mathbf{c})$ are the major species at high $\mathrm{Al} / \mathrm{Zr}$ ratios $(200-4000 \mathrm{~mol} / \mathrm{mol})$ [40]. It should be noted that the complexes (b) and (c) were suggested to be the precursors of active centers for polymerization [36]. In turn, the ${ }^{1} \mathrm{H}$ $\mathrm{NMR}$ analysis of the systems of $\mathrm{rac}-\mathrm{Et}(\mathrm{Ind})_{2} \mathrm{ZrCl}_{2}$ with $\mathrm{MAO}$, also at high $\mathrm{Al} / \mathrm{Zr}$ ratios $(300 \mathrm{~mol} / \mathrm{mol})$, showed one $\mu$-Me signal at $-0.85 \mathrm{ppm}$ (detected at $\mu$-Me signal as $\mathbf{b}$ in the case of $\mathrm{Cp}_{2} \mathrm{ZrCl}_{2} / \mathrm{MAO}$ ) indicating the formation of the $\left[\mathrm{rac}-\mathrm{Et}(\mathrm{Ind})_{2} \mathrm{Zr}(\mu-\mathrm{Me})_{2} \mathrm{AlMe}_{2}\right]^{+} \mathrm{Me}-\mathrm{MAO}^{-}$complex only [36].

Having the above results in mind, we performed the NMR analysis of the reaction products of $\mathrm{rac}-\mathrm{Et}(\mathrm{Ind}){ }_{2} \mathrm{ZrCl}_{2}$ with $\mathrm{MMAO}$, obtained in a wide range of $\mathrm{Al} / \mathrm{Zr}$ molar ratios $(\mathrm{Al} / \mathrm{Zr}=50$ to $1000 \mathrm{~mol} / \mathrm{mol}$ ), and of appropriate raw materials for reference. As can be seen from Figure 4, activation of $\mathrm{rac}-\mathrm{Et}(\mathrm{Ind}){ }_{2} \mathrm{ZrCl}_{2}$ by MMAO caused the down-field shift of the Ind- $\mathrm{C}_{5}{ }^{1} \mathrm{H} \mathrm{NMR}$ resonance of the ansa-metallocene catalyst, irrespective of the $\mathrm{Al} / \mathrm{Zr}$ molar ratios used (from 6.38 and $5.71 \mathrm{ppm}$ to 5.65 and $5.33 \mathrm{ppm}$, Figure 4a: 1-6). It should be noted that the presence of three resonances at 5.73, 5.40, and from 5.00 to $4.62 \mathrm{ppm}$ in MMAO (Figure 4a: 2) significantly impeded the investigation in all ${ }^{1} \mathrm{H}$ NMR spectra of the catalytic systems (Figure 4a: 3-7).
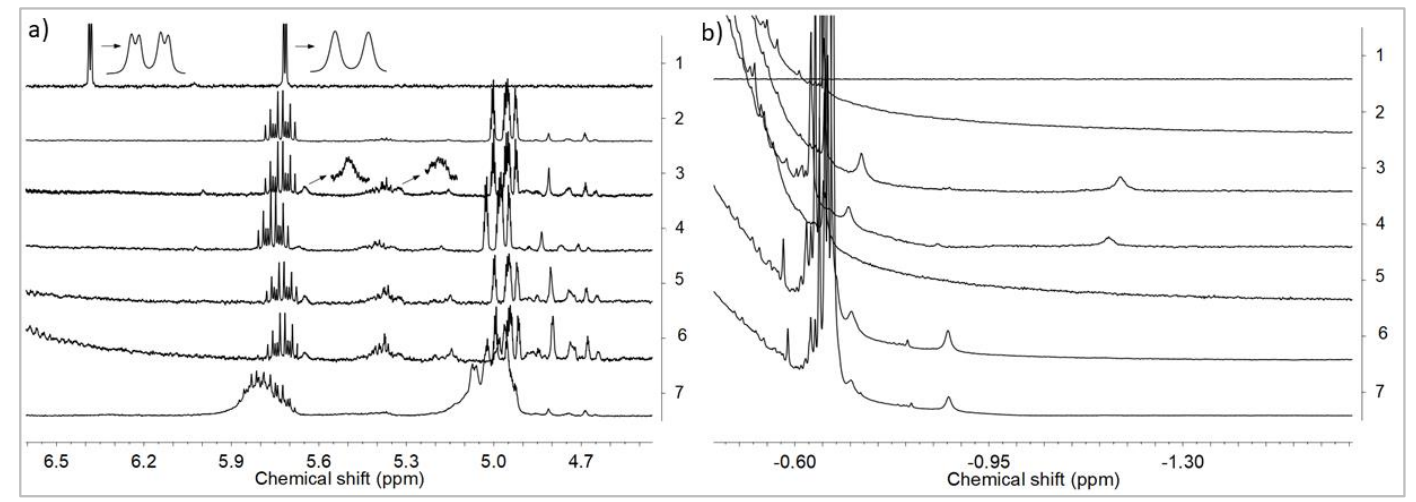

Figure 4. ${ }^{1} \mathrm{H}$ NMR spectra in two different ranges $(\mathbf{a}, \mathbf{b})$ in toluene-d8 at $20{ }^{\circ} \mathrm{C}$ of $\mathrm{rac}$ - $\mathrm{Et}(\mathrm{Ind})_{2} \mathrm{ZrCl}_{2}(1)$, MMAO (2), rac-Et(Ind) ${ }_{2} \mathrm{ZrCl}_{2}$ / MMAO: $\mathrm{Al} / \mathrm{Zr}=50$ (3), $\mathrm{Al} / \mathrm{Zr}=100$ (4), $\mathrm{Al} / \mathrm{Zr}=500$ (5), $\mathrm{Al} / \mathrm{Zr}=1000$ (6), and rac-Et(Ind) ${ }_{2} \mathrm{ZrCl}_{2} / \mathrm{MMAO} / \mathrm{POSS}-6-3: \mathrm{Al} / \mathrm{Zr}=50$ (7); $\left([\mathrm{Zr}]=1.25 \times 10^{-2} \mathrm{~mol} / \mathrm{dm}^{3}\right)$. 
Only two broadened resonances from Ind- $C_{5}$ were found in the ${ }^{1} \mathrm{H}$ NMR spectra (Figure 4a: 3 ) instead of the expected doublet of doublets $J_{\mathrm{HH}}=3.3$ and $0.7 \mathrm{~Hz}$ and doublet $J_{\mathrm{HH}}=3.3 \mathrm{~Hz}$ (Figure 4a: 1). The widths of the ${ }^{1} \mathrm{H}$ NMR peaks were probably affected by the exchange of the $\mathrm{Me}-\mathrm{MMAO}^{-}$counter-ions.

Moreover, the $\mu$-Me resonances of the ion pairs at $-1.2 \mathrm{ppm}$ (Figure $4 \mathrm{~b}: 3,4$ ) as well as at $-0.85 \mathrm{ppm}$ and $-0.75 \mathrm{ppm}$ were observed (Figure $4 \mathrm{~b}$ : 3-6). Taking into account the literature data concerning the NMR analysis of metallocene/MAO systems, these signals were assigned to the structure as shown in Figure 5.

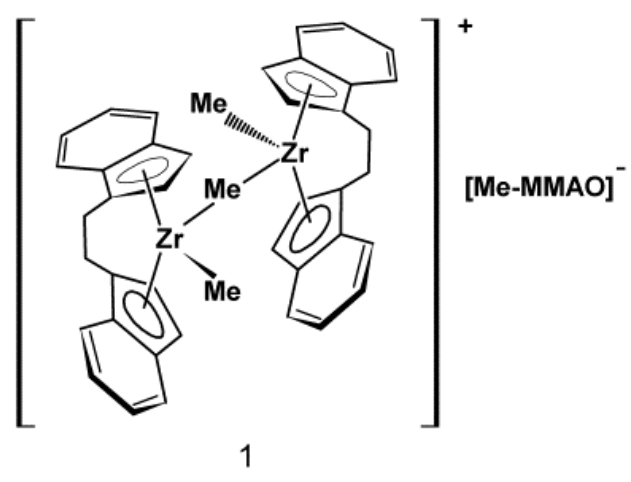

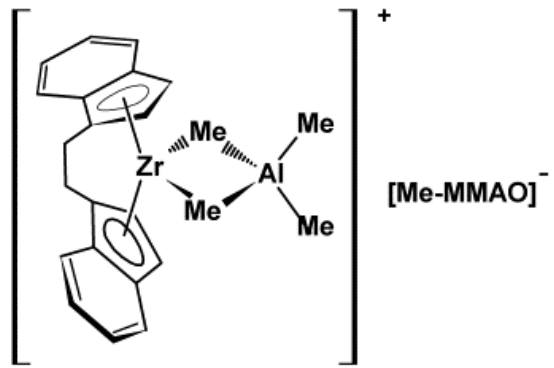

2

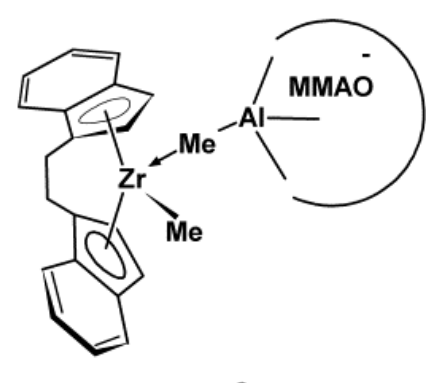

3

Figure 5. Proposed structures of catalytic intermediates formed within the $\mathrm{rac}-\mathrm{Et}(\mathrm{Ind})_{2} \mathrm{ZrCl}_{2} / \mathrm{MMAO}$ catalytic system for the range of $\mathrm{Al} / \mathrm{Zr}$ molar ratios used.

The concentrations of complexes $2(-0.85 \mathrm{ppm})$ and $3(-0.75 \mathrm{ppm})$ increased with the increasing $\mathrm{Al} / \mathrm{Zr}$ molar ratio. In turn, the complex 1 gradually disappeared at high $\mathrm{Al} / \mathrm{Zr}$ molar ratios which was confirmed by the decrease in the intensity of the $\mu$-Me resonance at $-1.2 \mathrm{ppm}$ (Figure 4b: 3-6). The cationic complexes 2 and 3 turned out to be the major species at high $\mathrm{Al} / \mathrm{Zr}$ ratios (500 and $1000 \mathrm{~mol} / \mathrm{mol}$ ) (Figure 4b: 6, 7) which was consistent with the published research reports (complexes b and c, respectively) [33-42].

It should be stressed, however, that to the best of our knowledge, the complete ansa-metallocene/MMAO/silsesquioxane system was never studied before by NMR. Meanwhile, it turned out in our research that the addition of the POSS-6-3 comonomer to the rac- $\mathrm{Et}(\mathrm{Ind})_{2} \mathrm{ZrMe}_{2} / \mathrm{MMAO}$ catalytic system, even at $\mathrm{Al} / \mathrm{Zr}=50 \mathrm{~mol} / \mathrm{mol}$, led to the disappearance of the $\mu$-Me resonance of the complex 1 at $-1.2 \mathrm{ppm}$ (Figure $4 \mathrm{~b}$ : 7). This phenomenon is associated with the influence of the POSS comonomer on transformation of the bimetallic metallocene species 1 (inactive form) into 2 or 3 complexes (precursors of the active form). However, the observed metallocene species 2 and 3 were dominant in the catalytic system in this case, even at the low $\mathrm{Al} / \mathrm{Zr}$ ratio of $50 \mathrm{~mol} / \mathrm{mol}$, which is unusual for this group of catalysts [33-42]. It is probable that the modification of the catalytic system by the POSS compound resulted in much higher activity of 
the catalytic system in ethylene copolymerization with the POSS-6-3 comonomer as compared to homopolymerization of ethylene (Figure 2).

Thus, the described results indicated that the POSS-6-3 compound acted not only as a comonomer but it also competed with MMAO for a bimetallic ion pair 1. Moreover, POSS-6-3 broke the methyl bridge in complex $\mathbf{1}$ and caused the active site to be readily accessible to MMAO.

The influence of the POSS-10-3 and POSS-10-4 comonomers on the rac-Et(Ind) $)_{2} \mathrm{ZrMe}_{2} / \mathrm{MMAO}$ catalytic system was further investigated for the adopted $\mathrm{Al} / \mathrm{Zr}$ molar ratio of $50 \mathrm{~mol} / \mathrm{mol}$. The POSS comonomers with longer alkenyl substituents were found not to affect the transformation of complex 1 into complex 2 or 3 , which was confirmed by the presence of the $\mu$-Me resonance at $-1.2 \mathrm{ppm}$ in ${ }^{1} \mathrm{H}$ NMR (Figure 6).

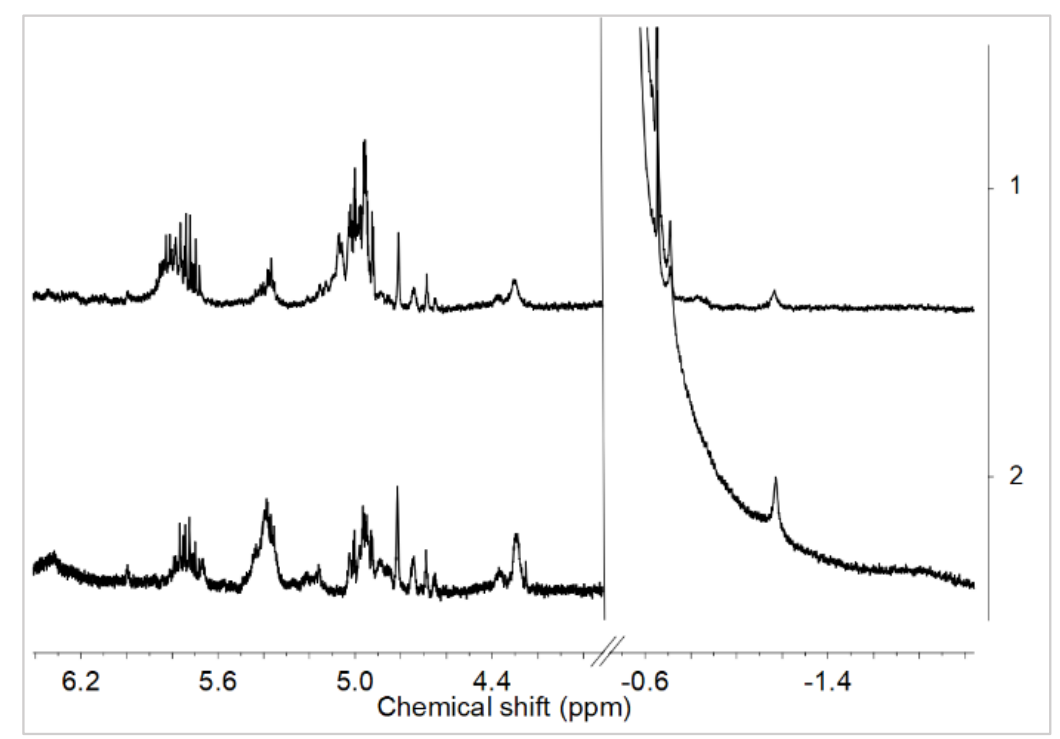

Figure 6. ${ }^{1} \mathrm{H}$ NMR spectra in toluene-d8 at $20{ }^{\circ} \mathrm{C}$ of $\mathrm{rac}-\mathrm{Et}(\mathrm{Ind})_{2} \mathrm{ZrCl}_{2} / \mathrm{MMAO} / \mathrm{POSS}-10-3: \mathrm{Al} / \mathrm{Zr}=50$ (1) and rac-Et(Ind) ${ }_{2} \mathrm{ZrCl}_{2} / \mathrm{MMAO} / \mathrm{POSS}-10-4: \mathrm{Al} / \mathrm{Zr}=50$ (2); $\left([\mathrm{Zr}]=1.25 \times 10^{-2} \mathrm{~mol} / \mathrm{dm}^{3}\right)$.

These results are consistent with the lower catalytic activity of the ansa-metallocene system in ethylene copolymerization with POSS-10-3 or POSS-10-4 in comparison to ethylene homopolymerization and especially to copolymerization of ethylene with POSS-6-3 (Figure 2).

\subsection{Structures of E/POSS Copolymers}

The contents of POSS units incorporated into the copolymer chain $\left(\mathrm{C}_{\mathrm{POSS}}\right)$ and the structures of copolymers were characterized by the ${ }^{1} \mathrm{H}$ and ${ }^{13} \mathrm{C}$ NMR (Figure 7) and FT-IR (Figure 8) methods.

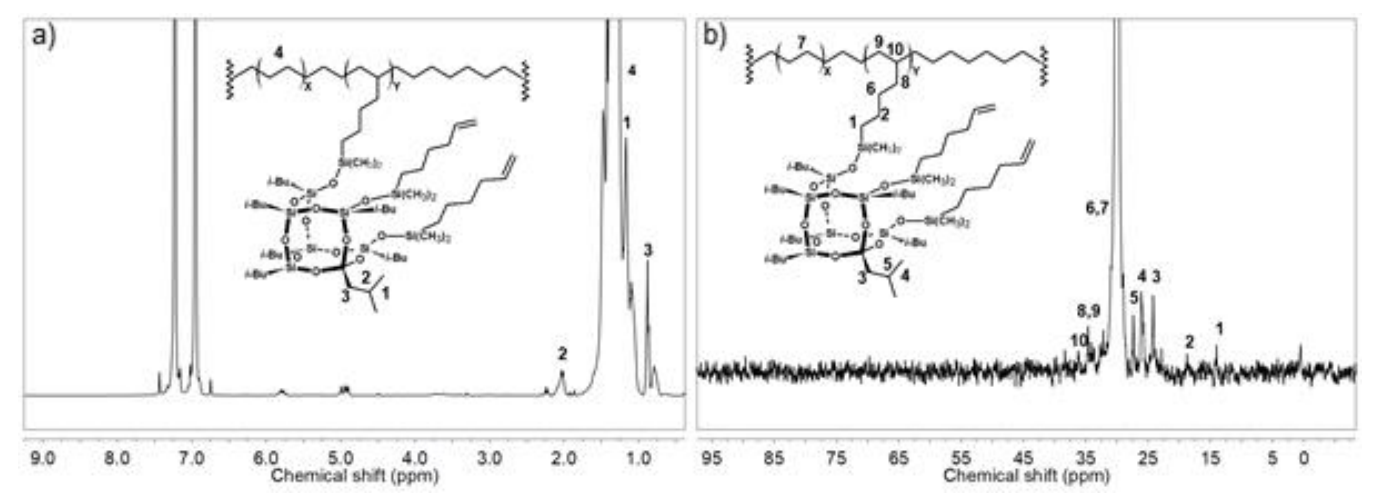

Figure 7. ${ }^{1} \mathrm{H}$ NMR (a) and ${ }^{13} \mathrm{C}$ NMR (b) spectra of E/POSS-6-3 copolymer. 
The signal pattern in the ${ }^{1} \mathrm{H}$ NMR spectrum (Figure 7a) is in agreement with the general pattern for ethylene copolymers with monoalkenyl(siloxy)- or monoalkenylsilsesquioxane derivatives [4-6,43]. Three signals at $0.87,1.10$, and $2.03 \mathrm{ppm}$ can be ascribed to the iso-butyl non-reactive substituent of the POSS units. A part of the $\left(\mathrm{CH}_{2}\right)_{\mathrm{x}}$ spacer of POSS leads to the signals in the same region of the spectrum as the polyethylene chain at about $1.32 \mathrm{ppm}$. The peaks assigned to chain unsaturation in copolymers occurred in the olefinic region (5.85-4.55 ppm). In the case of E/POSS copolymers, the ${ }^{13} \mathrm{C}$ NMR spectrum (Figure $7 \mathrm{~b}$ ) showed the signals at $14.01 \mathrm{ppm}\left(\mathrm{C}_{1}\right.$ in the spacer), $18.75 \mathrm{ppm}\left(\mathrm{C}_{2}\right.$ in the spacer), $29.98 \mathrm{ppm}\left(\mathrm{C}_{3}\right.$ in the spacer), and $34.64 \mathrm{ppm}\left(\mathrm{C}_{4}\right.$ in the spacer) for a part of the $\left(\mathrm{CH}_{2}\right)_{\times}$spacer that were unchanged after polymerization and similar to the peaks for the iso-butyl group at 24.16, 26.07 , and $27.35 \mathrm{ppm}$. The new peaks at $34.64\left(\mathrm{RCH}_{2}-\mathrm{CH}\right)$ and $36.21 \mathrm{ppm}\left(\mathrm{R}_{3} \mathrm{CH}\right)$ appeared due to the incorporation of POSS into the polymer chain.

A high intensity broad band with two maxima at $1130,1055 \mathrm{~cm}^{-1}$ in the FT-IR spectra of neat POSS comonomers (Figure 8) indicated the presence of Si-O-Si bonds occurring in the silicon-oxygen silsesquioxane cage $[44,45]$ and the bands at $1120,1060 \mathrm{~cm}^{-1}$ were ascribed to the $\mathrm{Si}-\mathrm{O}-\mathrm{Si}$ bonds in the dimethylsiloxy spacer linking the alkenyl reactive substituent with the silicon-oxygen cage [46]. In order to determine stability of the incompletely condensed POSS cage in the polymerization conditions, the $\mathrm{A}_{1120} / \mathrm{A}_{1060}$ and $\mathrm{A}_{1130} / \mathrm{A}_{1055}$ absorbance ratios were determined using the FT-IR spectra (Figure 8) of E/POSS copolymers. The absorbance ratio was equal to about 1.09 and 1.12 for copolymers with tri- and tetra-alkenyl-POSS, respectively. Thus, it could be concluded that the structures of the POSS comonomers remained unchanged during copolymerization.

a)

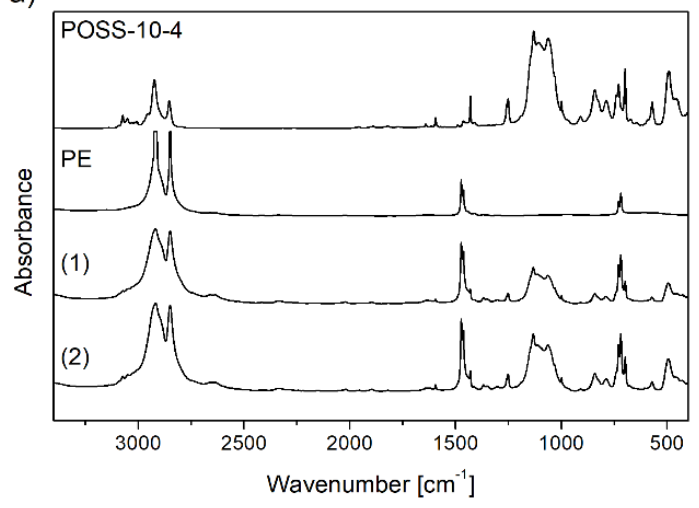

b)

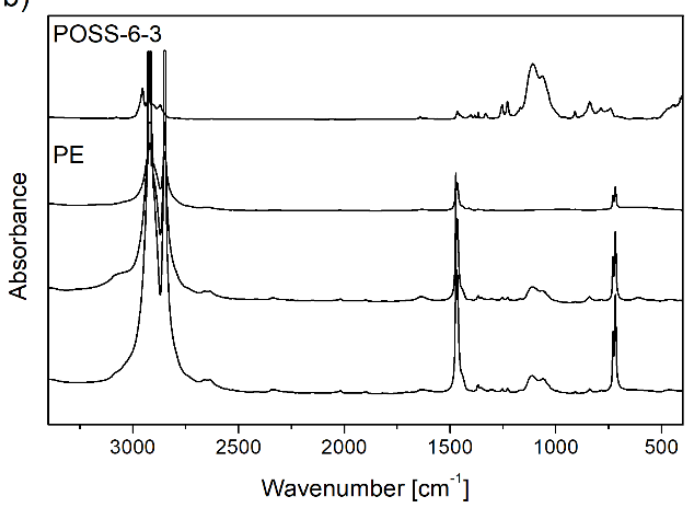

Figure 8. FT-IR spectra for neat POSS comonomers, polyethylenes, and E/POSS copolymers obtained over rac-Et(Ind) ${ }_{2} \mathrm{ZrCl}_{2}$ under ethylene pressure of $0.2 \mathrm{MPa}(\mathbf{a})$ and $0.5 \mathrm{MPa}(\mathbf{b})$ at the concentration of the POSS comonomer in the reaction feed of: $1.67 \times 10^{-3} \mathrm{~mol} / \mathrm{dm}^{3}(1)$ and $6.67 \times 10^{-3} \mathrm{~mol} / \mathrm{dm}^{3}(2)$.

The content of the POSS comonomer incorporated into the polymer chain was found to increase with the increasing comonomer concentration in the feed (Table 1).

Table 1. Compositions, molecular weights, and analysis of unsaturated end groups of E/POSS copolymers obtained with the use of $\mathrm{rac}-\mathrm{Et}(\mathrm{Ind}){ }_{2} \mathrm{ZrCl}_{2} / \mathrm{MMAO}$.

\begin{tabular}{|c|c|c|c|c|c|c|c|c|c|c|}
\hline \multirow[t]{2}{*}{ Item } & \multirow[t]{2}{*}{ (Co)polymers } & \multirow{2}{*}{$\frac{\mathbf{A}_{1120}}{\mathbf{A}_{2020}} \mathbf{f}$} & \multicolumn{2}{|c|}{$\mathrm{C}_{\text {POSS }}{ }^{\mathrm{e}}$} & \multirow[t]{2}{*}{$\mathrm{n}_{\mathrm{e}} \mathrm{e}^{\mathrm{s}}$} & \multirow[t]{2}{*}{$\mathrm{MD}^{\mathrm{e}}$} & \multirow{2}{*}{$\begin{array}{l}M_{\mathrm{w}} \cdot 10^{3} \\
(\mathrm{~g} / \mathrm{mol})^{\mathrm{g}}\end{array}$} & \multirow[t]{2}{*}{$\frac{M_{\mathrm{w}}}{M_{\mathrm{n}}} \mathrm{g}$} & \multicolumn{2}{|c|}{$\begin{array}{l}\text { Analysis of Unsaturated } \\
\text { End Groups } \mathrm{f}\end{array}$} \\
\hline & & & $(\mathrm{mol} \%)$ & (wt \%) & & & & & $\mathrm{A}_{908} / \mathrm{A}_{2020}$ & $\mathbf{A}_{800} / \mathbf{A}_{2020}$ \\
\hline 1 & PE & 0 & 0 & 0 & 0 & 0 & 165 & 1.9 & 0.460 & 0 \\
\hline $2^{a}$ & & 7.86 & 0.031 & 1.33 & 3226 & 99.969 & 326 & 3.9 & 0.649 & 0.145 \\
\hline $3^{b}$ & E/POSS-6-3 & 9.81 & 0.038 & 1.62 & 2632 & 99.962 & 364 & 4.0 & 0.857 & 0.110 \\
\hline $4^{b, c}$ & & 12.13 & 0.047 & 2.00 & - & - & - & - & 0.984 & 0.328 \\
\hline $5^{a}$ & & 8.83 & 0.034 & 1.65 & 2941 & 99.966 & 377 & 4.4 & 0.843 & 0.175 \\
\hline $6^{b}$ & E/POSS-10-3 & 9.98 & 0.040 & 1.94 & 2500 & 99.960 & 434 & 4.9 & 1.053 & 0.187 \\
\hline $7^{b, c}$ & & 8.25 & 0.031 & 1.51 & - & - & 526 & 4.8 & 0.769 & 0.541 \\
\hline
\end{tabular}


Table 1. Cont.

\begin{tabular}{|c|c|c|c|c|c|c|c|c|c|c|}
\hline \multirow[t]{2}{*}{ Item } & \multirow[t]{2}{*}{ (Co)polymers } & \multirow{2}{*}{${\frac{A_{1120}}{A_{2020}}}^{f}$} & \multicolumn{2}{|c|}{$\mathrm{C}_{\text {POss }}{ }^{\mathrm{e}}$} & \multirow[t]{2}{*}{$\mathbf{n}_{\mathrm{e}}{ }^{\mathrm{e}}$} & \multirow[t]{2}{*}{$\mathrm{MD}^{\mathrm{e}}$} & \multirow{2}{*}{$\begin{array}{l}M_{\mathrm{w}} \cdot 10^{3} \\
(\mathrm{~g} / \mathrm{mol}) \mathrm{g}\end{array}$} & \multirow{2}{*}{$\frac{M_{\mathrm{w}}}{M_{\mathrm{n}}} \mathrm{g}$} & \multicolumn{2}{|c|}{$\begin{array}{l}\text { Analysis of Unsaturated } \\
\text { End Groups }\end{array}$} \\
\hline & & & $(\mathrm{mol} \mathrm{\%})$ & $(w t \%)$ & & & & & $A_{908} / A_{2020}$ & $\mathbf{A}_{800} / \mathbf{A}_{2020}$ \\
\hline $8^{c, d}$ & PE & 0 & 0 & 0 & 0 & 0 & 226 & 3.9 & 0.291 & 0 \\
\hline $9^{\mathrm{a}, \mathrm{d}}$ & \multirow{3}{*}{ E/POSS-6-3 } & 14.46 & 0.056 & 2.37 & 1786 & 99.944 & - & - & 0.945 & 0.161 \\
\hline $10^{b, d}$ & & 23.78 & 0.093 & 3.87 & 1075 & 99.907 & - & - & 1.664 & 0 \\
\hline $11^{b, c, d}$ & & 16.43 & 0.064 & 2.70 & - & - & - & - & 0.928 & 0.463 \\
\hline $12^{\mathrm{a}, \mathrm{d}}$ & \multirow{3}{*}{ E/POSS-10-3 } & 14.66 & 0.057 & 2.74 & 1754 & 99.943 & - & - & 1.062 & 0 \\
\hline $13^{\mathrm{b}, \mathrm{d}}$ & & 17.46 & 0.068 & 3.25 & 1471 & 99.932 & - & - & 1.481 & 0.429 \\
\hline $14^{b, c, d}$ & & 11.07 & 0.043 & 2.08 & - & - & - & - & 1.337 & 0.309 \\
\hline $15^{\mathrm{a}, \mathrm{d}}$ & \multirow{2}{*}{ E/POSS-10-4 } & 19.11 & ${ }^{\mathrm{f}} 0.075$ & 4.74 & ${ }^{\mathrm{f}} 1333$ & 99.925 & - & - & 0.565 & 2.663 \\
\hline $16^{\mathrm{b}, \mathrm{c}}$ & & 30.76 & ${ }^{\mathrm{f}} 0.121$ & 7.43 & f 826 & 99.879 & - & - & 0.971 & 4.933 \\
\hline
\end{tabular}

The copolymers with higher contents of the POSS comonomers were obtained under lower ethylene pressure $\left(\mathrm{p}_{\mathrm{e}}=0.2 \mathrm{MPa}\right)$ during polymerization (Table 1 , items 2-7 and 9-14) which was associated with a higher probability of insertion of a comonomer segment into the $\mathrm{Zr}-\mathrm{C}$ bond. Interestingly, longer reaction times generally led to slightly lower incorporation of POSS into the copolymers, regardless of the reaction conditions (Table 1 , items $6,7,10,11,13,14$ ). This result could be explained by extremely high efficiency of the catalytic system in copolymerization of ethylene with POSS, which quickly decreased the POSS concentration in the feed at the initial stage of the copolymerization process.

The structures of the POSS comonomers strongly influenced POSS incorporation into the copolymer chain and the copolymers with POSS-10-4 obtained under $\mathrm{p}_{\mathrm{e}}=0.2 \mathrm{MPa}$ were characterized by the highest contents of the POSS units (up to $7.43 \mathrm{wt} \%$ ) (Table 1, item 16).

Despite the presence of three and four alkenyl substituents in the POSS comonomers, the incorporation degree of the POSS comonomer into the polymer chain was unexpectedly found lower in comparison with the DDSQ comonomer under the same reaction conditions $\left(C_{\mathrm{DDSQ}}=11.53 \mathrm{wt} \%\right)$ [17]. In the case of tri-alkenyl-POSS comonomers, in which the reactive substituents are close to each other, this phenomenon could be explained by the limited access to the active center.

For copolymers of ethylene with tri-alkenyl-POSS, the reactivity ratios of ethylene were calculated using the Fineman-Ross method [47]. It was found that the $r_{e}$ values were equal to 162 and 182 for copolymerization of E/POSS-6-3 and E/POSS-10-3, respectively. The resulting lower reactivity of the POSS-10-3 comonomer (higher $\mathrm{r}_{\mathrm{e}}$ value) could be explained by higher steric hindrance of the longer reactive group. Noteworthy is that the $r_{e}$ values in ethylene/tri-alkenyl-POSS copolymerization were comparable to the $r_{e}$ values for copolymerization with monoalkenyl(siloxy)and monoalkenylsilsesquioxanes [6], but they were much higher in comparison with the DDSQ comonomer [17]. Those results confirmed that the presence of three alkenyl substituents on the same side of the POSS cage did not increase reactivity of the POSS comonomer in copolymerization with ethylene. For all the obtained polymeric products, the number-average sequence length of ethylene $\left(\mathrm{n}_{\mathrm{e}}\right)$ and monomer dispersity (MD) were also determined (Table 1$)$.

The lowest values of $n_{e}$ were observed for E/POSS-10-4 copolymers in comparison to copolymers of ethylene with POSS-6-3 and POSS-10-3 which were obtained at the same polymerization conditions (Table 2). It should be noted that the $n_{e}$ values for ethylene copolymers with tri-alkenyl-POSS were similar to the values for copolymers which contained monoalkenyl(siloxy)or monoalkenylsilsesquioxanes [6]. Moreover, the $n_{e}$ values for E/POSS-10-4 copolymers were comparable to those values for E/DDSQ copolymers [17]. 
Table 2. Thermal properties of PE and E/POSS copolymers synthesized over the rac-Et(Ind $)_{2} \mathrm{ZrCl}_{2} / \mathrm{MMAO}$ catalytic system.

\begin{tabular}{|c|c|c|c|c|c|c|c|c|c|}
\hline \multirow[t]{2}{*}{ Item } & \multirow[t]{2}{*}{ (Co)polymers } & \multirow[t]{2}{*}{$T_{\mathrm{g}}\left[{ }^{\circ} \mathrm{C}\right]$} & \multirow[t]{2}{*}{$X_{c}{ }^{\mathrm{c}}[\%]$} & \multicolumn{4}{|c|}{ Melting Temperature ${ }^{c}$} & \multicolumn{2}{|c|}{$\begin{array}{l}\text { Crystallization } \\
\text { Temperature }^{c}\end{array}$} \\
\hline & & & & $T_{\text {mo }}$ & $T_{\mathrm{mp}}$ & $T_{\text {me }}$ & $T_{\text {co }}$ & $T_{\mathrm{cp}}$ & $T_{\mathrm{ce}}$ \\
\hline 1 & $\mathrm{PE}^{\mathrm{e}}$ & -149.7 & 63.2 & 124.8 & 131.0 & 136.4 & 119.7 & 116.5 & 111.9 \\
\hline $2^{a}$ & \multirow{2}{*}{ E/POSS-6-3 ${ }^{e}$} & -156.0 & 60.9 & 122.4 & 134.8 & 140.1 & 121.4 & 115.6 & 106.8 \\
\hline $3^{b}$ & & -157.1 & 59.1 & 125.4 & 132.3 & 135.6 & 120.1 & 118.2 & 114.1 \\
\hline $4^{\mathrm{a}}$ & \multirow{2}{*}{ E/POSS-10-3 ${ }^{e}$} & -166.5 & 58.5 & 122.5 & 134.3 & 138.3 & 120.8 & 115.1 & 108.2 \\
\hline $5^{b}$ & & -166.6 & 60.4 & 124.2 & 133.6 & 140.3 & 120.2 & 116.4 & 107.4 \\
\hline 6 & $P E^{d}$ & -155.0 & 61.2 & 123.2 & 128.6 & 134.6 & 119.8 & 116.5 & 112.8 \\
\hline $7^{\mathrm{a}}$ & \multirow{2}{*}{ E/POSS-6-3 ${ }^{d}$} & -157.8 & 56.2 & 121.7 & 132.2 & 135.9 & 120.5 & 116.4 & 108.8 \\
\hline $8^{b}$ & & -158.0 & 56.7 & 121.8 & 131.0 & 135.9 & 120.1 & 116.3 & 108.9 \\
\hline $9^{a}$ & \multirow{2}{*}{ E/POSS-10-3 ${ }^{d}$} & -157.3 & 54.7 & 119.3 & 129.8 & 133.6 & 119.8 & 115.1 & 108.2 \\
\hline $10^{\mathrm{b}}$ & & -162.5 & 50.6 & 122.0 & 129.4 & 135.7 & 118.6 & 116.0 & 108.2 \\
\hline 11 & $P E^{d}$ & -159.3 & 62.2 & 123.2 & 129.6 & 134.6 & 119.8 & 117.5 & 112.8 \\
\hline $12^{\mathrm{a}}$ & \multirow{2}{*}{ E/POSS- $10-4^{d}$} & -150.4 & 53.7 & 116.4 & 129.5 & 135.4 & 119.0 & 114.7 & 104.7 \\
\hline $13^{b}$ & & -149.5 & 50.2 & 117.2 & 127.9 & 132.5 & 118.4 & 114.7 & 106.0 \\
\hline
\end{tabular}

The monomer dispersity (MD) values were equal to about 100 irrespective of the kind of the POSS comonomer (Table 1) which suggested that the POSS units were incorporated into the polymer chain between long ethylene sequences.

The molecular weights $\left(M_{\mathrm{W}}\right)$ of the E/tri-alkenyl-POSS copolymers synthesized by rac-Et(Ind $)_{2} \mathrm{ZlCl}_{2}$ were much higher in comparison to neat polyethylene, which suggested that chain termination by transfer to the monomer was significantly limited (Figure 9, Table 1). However, it should be noted that it was impossible for the E/POSS-10-4 copolymers to determine the $M_{\mathrm{w}}$ and $M_{\mathrm{w}} / M_{\mathrm{n}}$ values by the GPC analysis because their solubility was only partial.

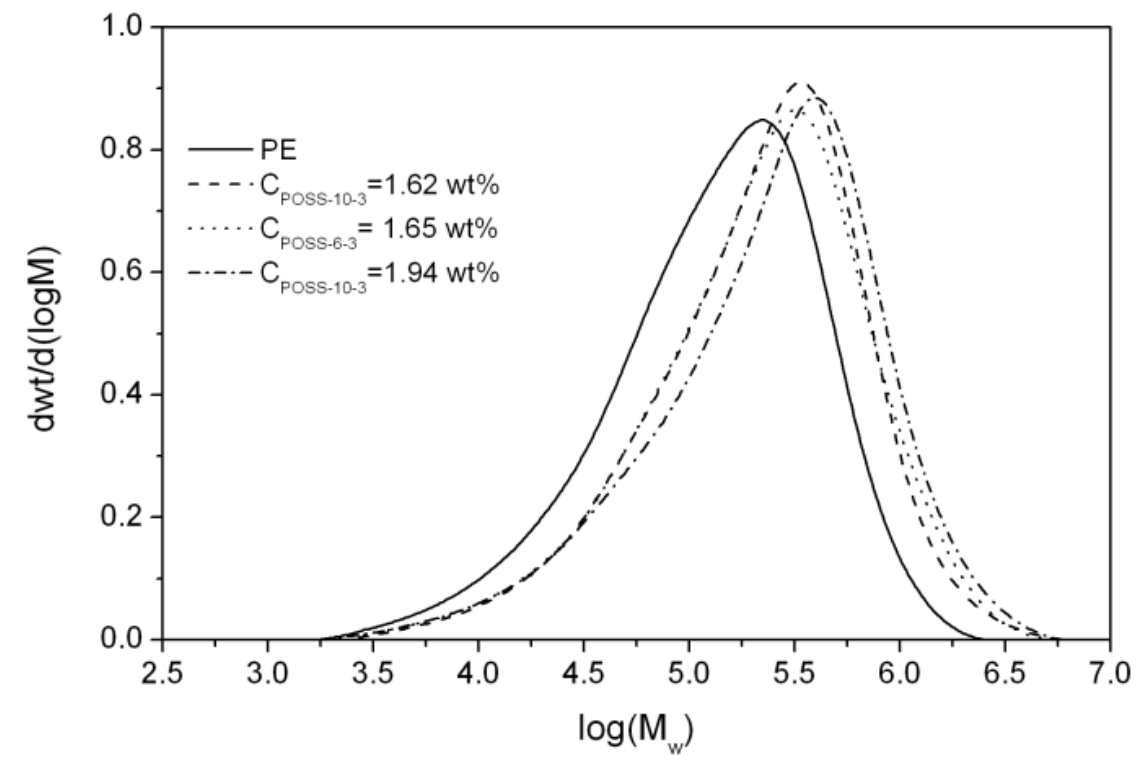

Figure 9. GPC curves for polyethylene and $\mathrm{E} / \mathrm{POSS}$ copolymers obtained by the $\mathrm{rac}-\mathrm{Et}(\mathrm{Ind})_{2} \mathrm{ZrCl}_{2}$ catalyst.

Moreover, the $M_{\mathrm{W}}$ values of E/POSS increased with the increasing POSS content in the copolymer. This indicated the modifying influence of the tri-alkenyl-POSS comonomer on metallocene active 
sites, irrespective of the kind of reactive substituents present in the comonomer used. Based on the literature data [3-6], such phenomenon was for the first time observed in the case of ethylene copolymerization with POSS, which was catalyzed by the metallocene system. It could be explained by the interaction of incompletely condensed silicon-oxygen of the POSS comonomer with the active center of ansa-metallocene (as was previously suggested on the basis of the ${ }^{1} \mathrm{H}$ NMR analysis of the complexes) or by the influence of the POSS comonomer on the formation of the ion pair, which resulted in many "open" active sites of the catalysts for the monomer insertion.

All metallocene-synthesized (co)polymers as described above were characterized by the unimodal but relatively broad molecular weight distributions $\left(M_{\mathrm{w}} / M_{\mathrm{n}}=3.9-4.9\right)$ (Figure 9, Table 1). The copolymers characterized by broader molecular weight distributions were obtained when the POSS-10-3 comonomers were used in comparison to POSS-6-3, probably due to the higher POSS content in the copolymer.

The analysis of specific unsaturated end groups by the ${ }^{1} \mathrm{H}$ NMR and FT-IR spectra for the E/POSS copolymers revealed the presence of only vinyl and tri-substituted vinylene groups (Figure 10, Table 1).

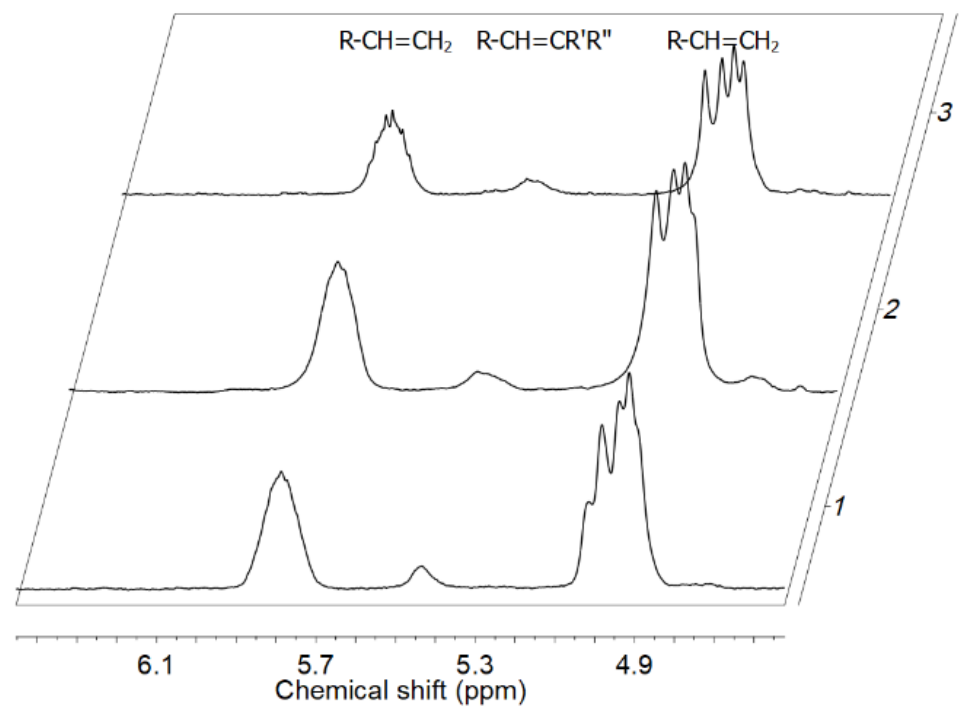

Figure 10. Unsaturation region in ${ }^{1} \mathrm{H}$ NMR spectra of E/POSS-10-3 copolymers for various contents of POSS: $1.65 \mathrm{wt} \%$ (1), $1.94 \mathrm{wt} \%$ (2), $3.25 \mathrm{wt} \%$ (3).

The absence of vinylidene and trans-vinylene end groups indicated that tri- and tetra-alkenyl-silsesquioxane did not take part in chain termination after 1,2 and 2,1-insertion of the POSS comonomer (Figure 10, Table 1) which was in line with the changes in molecular weights of the copolymers. The relative amounts of end groups increased with the increasing POSS content in the copolymers, regardless of the kind of the POSS comonomer (Table 1). The presence of trisubstituted vinylene end group in the copolymers suggested that the POSS comonomers were incorporated internally into the polymer chains [48].

Moreover, the increase in the content of vinyl end groups and increased $M_{\mathrm{w}}$ values with the increasing contents of POSS in copolymers indicated that not all alkenyl substituents of POSS took part in copolymerization. Therefore, one should consider different ways of incorporation of these multi-functional POSS units into the copolymer chains.

It is theoretically possible to obtain the macromolecules with POSS as pendant vinyl groups (type I), cyclic units (type II), and copolymers with cross-linked structures (type III) analogously to previously investigated ethylene/DDSQ copolymers [17].

In the case of ethylene copolymerization with the POSS comonomers which contain the reactive substituents located close to each other, the formation of cyclic units in the polymer chain could be expected (Figure 11, type II). However, the absorption band at $945 \mathrm{~cm}^{-1}$ associated with the cyclic 
structure in the main chain is not observed [49]. Noteworthy is that the relative content of vinyl groups in the case of the E/POSS-10-4 copolymer was much lower in comparison to the products with POSS-6-3 and POSS-10-3 obtained at the same reaction conditions (Table 1, items 6-11).

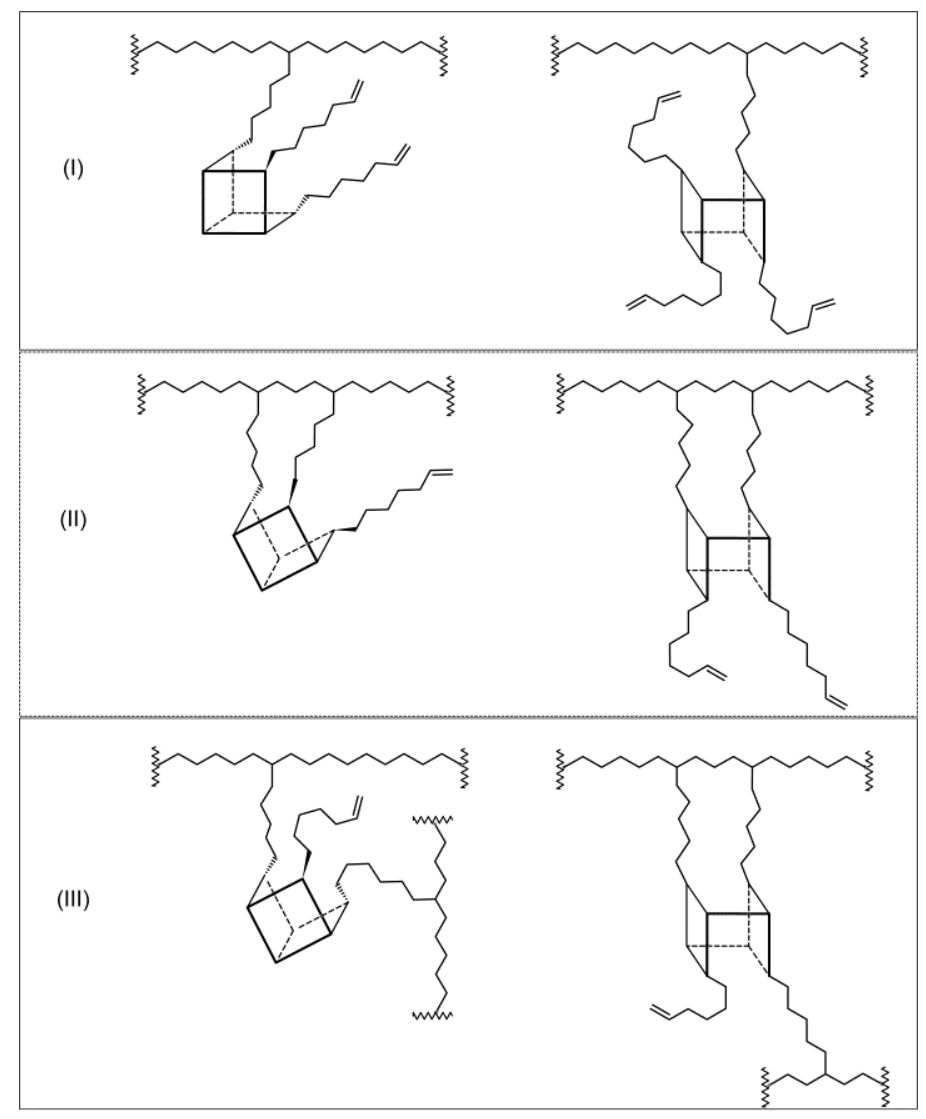

Figure 11. Some possible ways of incorporation of tri- or tetra-alkenyl-POSS comonomers into the polymer chain for ethylene/POSS copolymers: POSS as a pendant group (type I), intermolecular cyclic group (type II), and POSS as a cross-linking agent (type III).

It is suggested that tetra-alkenyl-POSS acted as a cross-linking agent (Figure 11, type III) due to the presence of reactive alkenyl substituents on both sides of the silicon-oxygen cage, which resulted in lower steric hindrance in comparison to tri-alkenyl-POSS.

For copolymers of ethylene with tetra-alkenyl-POSS, the content of the cross-linked fraction as determined by estimation of the gel content $(G)$ increased with the increasing content of POSS in the copolymer. It should be noted that the gel content for tetra-alkenyl-POSS-containing copolymers was higher (from $53.0 \%$ to $81.3 \%$ ) in comparison to copolymers with the DDSQ comonomer (up to 65.0\%) [17] despite the fact that the contents of POSS-10-4 were lower in the copolymer. This could be associated with the presence of four reactive substituents in the POSS-10-4 comonomer and hence its greater ability to create cross-linked structures.

The incorporation of the POSS-10-4 comonomers into the polymer chain increased the $T_{\mathrm{g}}$ values significantly with the increasing POSS content (Figure $12 \mathrm{~b}$ and Table 2) which was associated with the lower flexibility of the copolymer chain and which confirmed the cross-linked structure of the E/POSS-10-4 copolymer (Figure 11, type III).

In turn, the glass transition temperature $\left(T_{\mathrm{g}}\right)$ of the ethylene copolymers with tri-alkenyl-POSS slightly decreased with the increasing contents of POSS in the copolymer (Figure 12 and Table 2). This change of the $T_{\mathrm{g}}$ value was basically in parallel with relative amounts of vinyl end groups and it indicated the presence of vinyl pendant groups. 

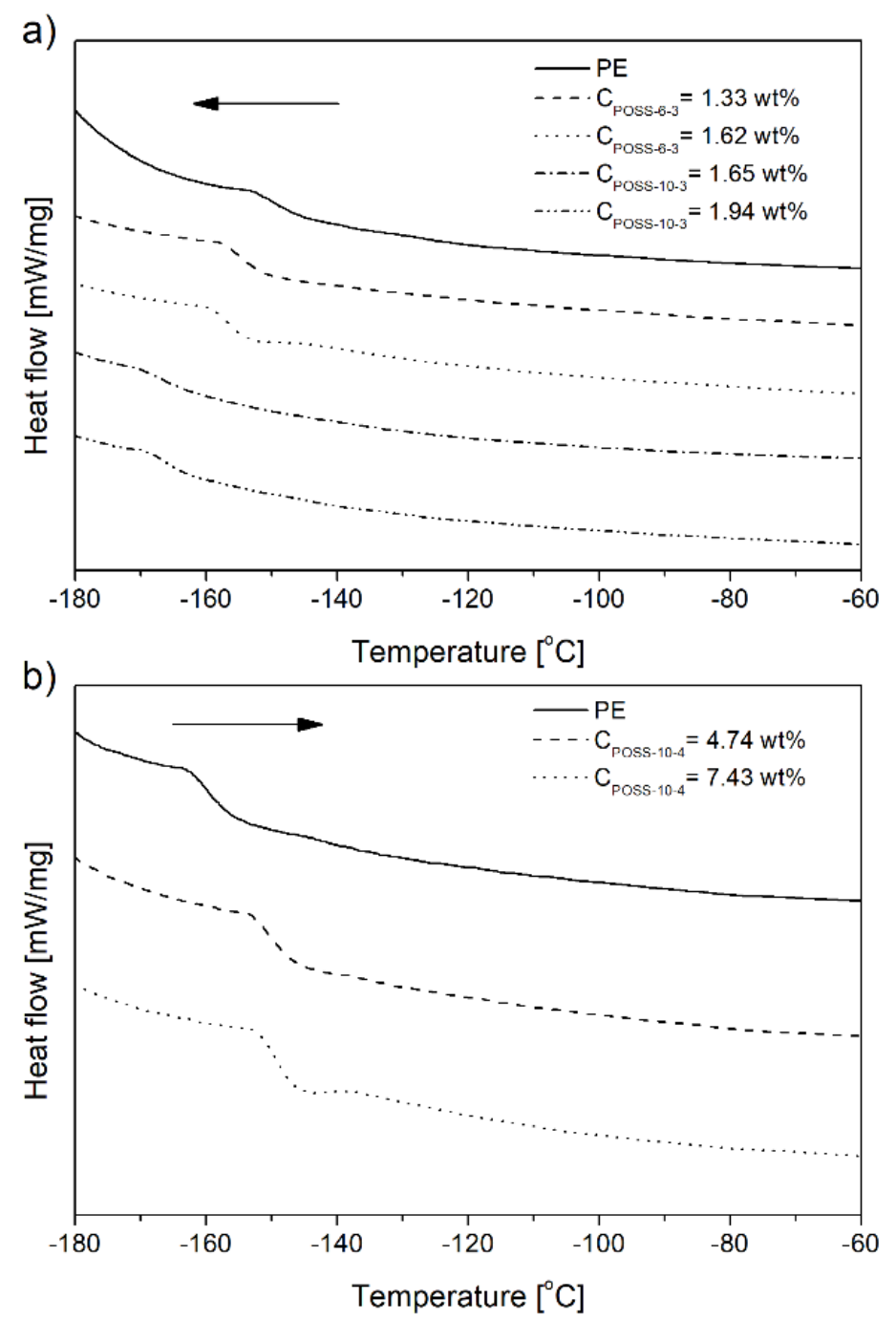

Figure 12. DSC curves of glass transition of selected ethylene copolymers with tri- (a) or tetra-alkenyl-silsesquioxane (b).

Their increased contents in the copolymer resulted in lower $T_{\mathrm{g}}$ values (Figure 12a and Tables 1 and 2) due to the absence of sterically rigid cyclic and cross-linked units (Figure 11, type II and III). The similar changes in $T_{\mathrm{g}}$ caused by incorporation of sterically encumbered monomer units, like cyclic rings, was reported in the literature related to ethylene copolymerization with unconjugated dienes [50].

\subsection{Crystallization and Melting Behavior of E/POSS Copolymers}

The increasing POSS content in copolymers decreased the values of the crystallinity degree $\left(X_{\mathrm{c}}\right)$ and peak melting temperature $\left(T_{\mathrm{mp}}\right)$, regardless of the kind of the POSS comonomer (Table 2). These results indicate that incorporation of the POSS comonomer in the copolymer resulted in disruption of regular packing of macromolecules.

The endothermic peaks in the DSC curves of the copolymers were observed to get broader with the increasing POSS incorporation degree, which proved the increased heterogeneity of the copolymer, irrespective of the kind of POSS applied (Figure 13, Table 2). This phenomenon could be confirmed also by the shapes of $T_{\mathrm{g}}$ curves (Figure 12a). 
a)

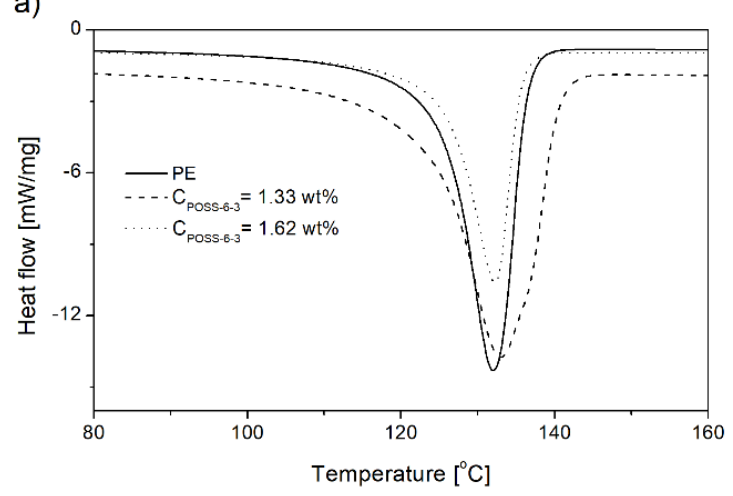

b)

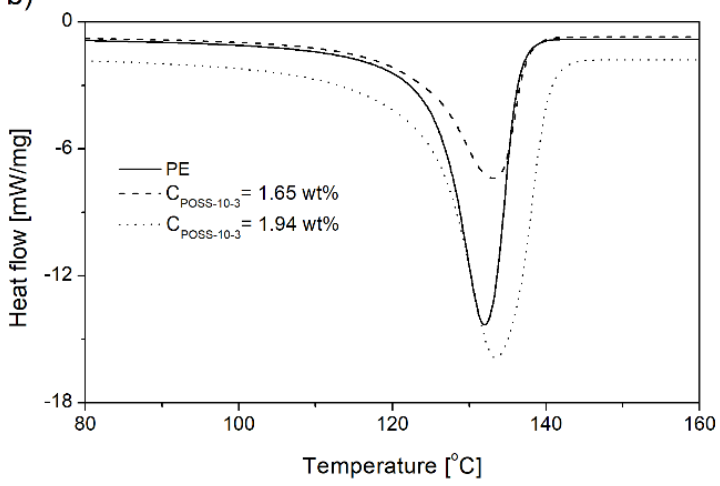

Figure 13. DSC curves of neat polyethylene and $\mathrm{E} / \mathrm{POSS}$ copolymers synthesized by rac- $\mathrm{Et}(\mathrm{Ind})_{2} \mathrm{ZrCl}_{2}$ $\left(\mathrm{p}_{\mathrm{e}}=0.5 \mathrm{MPa}\right)(\mathbf{a}, \mathbf{b})$.

The values of $T_{\mathrm{cp}}$ for the copolymers generally occurred at lower temperatures in comparison to neat polyethylene and they decreased with the increasing POSS comonomer content (Table 2). Moreover, broader exothermic peaks were observed for the copolymers produced under $\mathrm{p}_{\mathrm{e}}=0.2 \mathrm{MPa}$ in comparison to neat polyethylene which increased with the increasing contents of the POSS units in the copolymers (Table 2, items 6-13). This phenomenon could be associated with the increased heterogeneity of the chain composition of the E/POSS copolymers. The opposite relation was observed for the E/POSS-6-3 copolymers obtained under higher ethylene pressure for which narrower exothermic peaks were visible, which suggested acceleration of the crystallization process (Table 2, items 1-5).

\section{Conclusions}

The hybrid copolymers of ethylene with open-caged iso-butyl-substituted tri-alkenyl-silsesquioxanes (POSS-6-3 and POSS-10-3) and phenyl-substituted tetra-alkenyl-silsesquioxane (POSS-10-4) were for the first time successfully synthesized by coordinative copolymerization with the use of the metallocene catalytic system ( $\mathrm{rac}-\mathrm{Et}(\mathrm{Ind})_{2} \mathrm{ZrCl}_{2} / \mathrm{MMAO}$ ).

The performance of copolymerization was found to be significantly affected by the kind and concentration of the silsesquioxane comonomer in the feed as well as by the ethylene pressure and reaction time. The steric hindrance, inductive effect, and interactions between the open silicon-oxygen cage of the POSS comonomers and the active center of the metallocene catalyst significantly influenced the efficiency of polymerization. In the case of E/POSS-6-3 copolymerization, a very high catalyst activity (up to $21,740 \mathrm{~kg}_{\text {copolymer }} / \mathrm{mol}_{\mathrm{Zr}} \times 0.5 \mathrm{~h}$ ) was noted. Moreover, the positive comonomer effect was observed for the first time in the ethylene/POSS copolymerization.

Based on the ${ }^{1} \mathrm{H}$ NMR results, POSS-6-3 was found to act as a modifier of the catalytic system which caused the increased concentration of complexes $\mathbf{2}$ or $\mathbf{3}$ (precursors of active forms) at the very low $\mathrm{Al} / \mathrm{Zr}$ ratio (50) which is atypical for the metallocene catalysts.

The E/POSS copolymers varied in the POSS contents, reaching up to $7.43 \mathrm{wt} \%$ in the case of the E/POSS-10-4 copolymer. Incorporation of the POSS comonomers into the polymer chains resulted in the increase in the molecular weights which indicated the limitation of chain termination by transfer to the monomer and suggested the modifying influence of the POSS comonomer on the metallocene active sites. Depending on the functionality of the POSS comonomer, copolymers varied in the structural architecture. Tri-alkenyl-silsesquioxanes were incorporated into the polymer chains as pendant groups. In the case of copolymers with tetra-alkenyl-silsesquioxane, the cross-linked structure was demonstrated and the gel content reached even $81.3 \%$. These structural differences were proved by the changes in the contents of unsaturated end groups and by the glass transition temperature 
values. The copolymers of ethylene with multi-alkenyl-POSS were also characterized by interesting melting and crystallization behavior.

Acknowledgments: This work was financially supported by the National Science Centre of Poland (NCN), under the OPUS 4 research scheme, grant number: DEC-2012/07/B/ST5/03042.

Author Contributions: Paweł Groch, Katarzyna Dziubek and Krystyna Czaja conceived and designed the experiments; Paweł Groch performed most experiments; Paweł Groch analyzed the data; Katarzyna Mituła, Beata Dudziec prepared POSS comonomers; Paweł Groch, Katarzyna Dziubek, Krystyna Czaja wrote the paper.

Conflicts of Interest: The authors declare no conflict of interest.

\section{References}

1. Baney, R.H.; Itoh, M.; Sakakibara, A.; Suzuki, T. Silsesquioxanes. Chem. Rev. 1995, 95, 1409-1430. [CrossRef]

2. Kickelbick, G. Introduction to Hybrid Materials. In Hybrid Materials; Wiley-VCH Verlag GmbH \& Co., KGaA: Weinheim, Germany, 2007; pp. 1-48.

3. Tsuchida, A.; Bolln, C.; Sernetz, F.G.; Frey, H.; Mülhaupt, R. Ethene and propene copolymers containing silsesquioxane side groups. Macromolecules 1997, 30, 2818-2824. [CrossRef]

4. Zhang, H.-X.; Shin, Y.-J.; Yoon, K.-B.; Lee, D.-H. Preparation and properties of propylene/POSS copolymer with rac-Et(Ind $)_{2} \mathrm{ZrCl}_{2}$ catalyst. Eur. Polym. J. 2009, 45, 40-46. [CrossRef]

5. Zhang, H.-X.; Jung, M.-S.; Shin, Y.-J.; Yoon, K.-B.; Lee, D.-H. Preparation and properties of ethylene/POSS copolymer with rac-Et(Ind) ${ }_{2} \mathrm{ZrCl}_{2}$ catalyst. J. Appl. Polym. Sci. 2009, 111, 2697-2702. [CrossRef]

6. Groch, P.; Dziubek, K.; Czaja, K.; Dudziec, B.; Marciniec, B. Copolymers of ethylene with monoalkenyl- and monoalkenyl(siloxy)silsesquioxane (POSS) comonomers-Synthesis and characterization. Eur. Polym. J. 2017, 90, 368-382. [CrossRef]

7. Liu, N.; Li, L.; Wang, L.; Zheng, S. Organic-inorganic polybenzoxazine copolymers with double decker silsesquioxanes in the main chains: Synthesis and thermally activated ring-opening polymerization behavior. Polymer 2017, 109, 254-265. [CrossRef]

8. Hao, J.; Wei, Y.; Chen, B.; Mu, J. Polymerization of polyhedral oligomeric silsequioxane (POSS) with perfluoro-monomers and a kinetic study. RSC Adv. 2017, 7, 10700-10706. [CrossRef]

9. Wu, S.; Hayakawa, T.; Kikuchi, R.; Grunzinger, S.J.; Kakimoto, M.-A.; Oikawa, H. Synthesis and characterization of semiaromatic polyimides containing POSS in main chain derived from double-decker-shaped silsesquioxane. Macromolecules 2007, 40, 5698-5705. [CrossRef]

10. Wu, S.; Hayakawa, T.; Kakimoto, M.-A.; Oikawa, H. Synthesis and characterization of organosoluble aromatic polyimides containing POSS in main chain derived from double-decker-shaped silsesquioxane. Macromolecules 2008, 41, 3481-3487. [CrossRef]

11. Liu, N.; Wei, K.; Wang, L.; Zheng, S. Organic-inorganic polyimides with double decker silsesquioxane in the main chains. Polym. Chem. 2016, 7, 1158-1167. [CrossRef]

12. Miyasaka, M.; Fujiwara, Y.; Kudo, H.; Nishikubo, T. Synthesis and characterization of hyperbranched polymer consisting of silsesquioxane derivatives. Polym. J. 2010, 42, 799-803. [CrossRef]

13. Wei, K.; Wang, L.; Li, L.; Zheng, S. Synthesis and characterization of bead-like poly(N-isopropylacrylamide) copolymers with double decker silsesquioxane in the main chains. Polym. Chem. 2015, 6, 256-269. [CrossRef]

14. Huang, J.; Jiang, P.; Wen, Y.; Deng, J.; He, J. Soy-castor oil based polyurethanes with octaphenylsilsesquioxanetetraol double-decker silsesquioxane in the main chains. RSC Adv. 2016, 6, 69521-69529. [CrossRef]

15. Zhang, W.; Xu, J.; Li, X.; Song, G.; Mu, J. Preparation, characterization, and properties of poly(aryl ether sulfone) systems with double-decker silsesquioxane in the main chains by reactive blending. J. Polym. Sci. Part A Polym. Chem. 2014, 52, 780-788. [CrossRef]

16. Żak, P.; Dudziec, B.; Dutkiewicz, M.; Ludwiczak, M.; Marciniec, B.; Nowicki, M. A new class of stereoregular vinylene-arylene copolymers with double-decker silsesquioxane in the main chain. J. Polym. Sci. Part A Polym. Chem. 2016, 54, 1044-1055. [CrossRef]

17. Groch, P.; Dziubek, K.; Czaja, K.; Białek, M.; Mituła, K.; Dudziec, B.; Marciniec, B. Synthesis and structural characterization of ethylene copolymers containing double-decker silsesquioxane as pendant groups and cross-linkage sites by coordinative copolymerization. Eur. Polym. J. 2018, 100C, 187-199. [CrossRef] 
18. Liu, N.; Zheng, S. Organic-inorganic poly( $N$-vinylpyrrolidone) copolymers with double-decker silsesquioxane in the main chains: Synthesis, glass transition, and self-assembly behavior. J. Polym. Sci. Part A Polym. Chem. 2016, 54 18, 2949-2961. [CrossRef]

19. Chen, D.; Yi, S.; Fang, P.; Zhong, Y.; Huang, C.; Wu, X. Synthesis and characterization of novel room temperature vulcanized (RTV) silicone rubbers using octa[(trimethoxysilyl)ethyl]-POSS as cross-linker. React. Funct. Polym. 2011, 71, 502-511. [CrossRef]

20. Liu, H.; Zheng, S.; Nie, K. Morphology and Thermomechanical Properties of Organic-Inorganic Hybrid Composites Involving Epoxy Resin and an Incompletely Condensed Polyhedral Oligomeric Silsesquioxane. Macromolecules 2005, 38, 5088-5097. [CrossRef]

21. Matějka, L.; Strachota, A.; Pleštil, J.; Whelan, P.; Steinhart, M.; Šlouf, M. Epoxy Networks Reinforced with Polyhedral Oligomeric Silsesquioxanes (POSS). Structure and Morphology. Macromolecules 2004, 37, 9449-9456. [CrossRef]

22. Strachota, A.; Kroutilová, I.; Kovářová, J.; Matějka, L. Epoxy Networks Reinforced with Polyhedral Oligomeric Silsesquioxanes (POSS). Thermomechanical Properties. Macromolecules 2004, 37, 9457-9464. [CrossRef]

23. Yusa, S.; Ohno, S.; Honda, T.; Imoto, H.; Nakao, Y.; Naka, K.; Nakamura, Y.; Fujii, S. Synthesis of silsesquioxane-based element-block amphiphiles and their self-assembly in water. RSC Adv. 2016, 6, 73006-73012. [CrossRef]

24. Mituła, K.; Dutkiewicz, M.; Dudziec, B.; Marciniec, B.; Czaja, K. A library of monoalkenylsilsesquioxanes as potential comonomers for synthesis of hybrid materials. J. Therm. Anal. Calorim. 2017, in review.

25. Mituła, K.; Duszczak, J.; Brzakalski, D.; Dudziec, B.; Kubicki, M.; Marciniec, B. Tetra-functional double-decker silsesquioxanes as anchors for reactive functional groups and potential synthons for hybrid materials. Chem. Commun. 2017, 53, 10370-10373. [CrossRef] [PubMed]

26. Mituła, K.; Dudziec, B.; Marciniec, B. Synthesis of dialkenyl-substituted double-decker silsesquioxanes as precursors for linear copolymeric systems. J. Inorg. Organomet. Polym. Mater. 2017, 1-8. [CrossRef]

27. Widman, G.; Riesen, R. Thermal Analysis: Terms, Methods, Application; Alfred Huthing Verlag: Heidelberg, Germany, 1987.

28. Kaminsky, W.; Laban, A. Metallocene catalysis. Appl. Catal A Gen. 2001, 222, 47-61. [CrossRef]

29. Lipponen, S.H.; Seppälä, J.V. Ethylenebis(indenyl)zirconium dichloride/methylaluminoxane-catalyzed copolymerization of ethylene and 1-alkene-n-trimethylsilanes. Organometallics 2011, 30, 528-533. [CrossRef]

30. Hu, P.; Wang, J.-Q.; Wang, F.; Jin, G.-X. Preparation, Structure, and Ethylene (Co)Polymerization Behavior of Group IV Metal Complexes with an [OSSO]-Carborane Ligand. Chem. Eur. J. 2011, 17, 8576-8583. [CrossRef] [PubMed]

31. Kaminsky, W.; Winkelbach, H. Influence of supported metallocene catalysts on polymer tacticity. Top. Catal. 1999, 7, 61-67. [CrossRef]

32. Olabisi, O.; Atiqullah, M.; Kaminsky, W. Group 4 Metallocenes: Supported and Unsupported. J. Macromol. Sci. C 1997, 37, 519-554. [CrossRef]

33. Tritto, I.; Donetti, R.; Sacchi, M.C.; Locatelli, P.; Zannoni, G. Dimethylzirconocene-Methylaluminoxane Catalyst for Olefin Polymerization: NMR Study of Reaction Equilibria. Macromolecules 1997, 30, 1247-1252. [CrossRef]

34. Lyakin, O.Y.; Bryliakov, K.P.; Semikolenova, N.V.; Lebedev, A.Y.; Voskoboynikov, A.Z.; Zakharov, V.A.; Talsi, E.P. ${ }^{1} \mathrm{H}$ and ${ }^{13} \mathrm{C}$ NMR Studies of Cationic Intermediates Formed upon Activation of "Oscillating" Catalyst (2-PhInd) $)_{2} \mathrm{ZrCl}_{2}$ with $\mathrm{MAO}, \mathrm{MMAO}$, and $\mathrm{AlMe}_{3} /\left[\mathrm{CPh}_{3}\right]^{+}\left[\mathrm{B}\left(\mathrm{C}_{6} \mathrm{~F}_{5}\right)_{4}\right]$. Organometallics 2007, 26, 1536-1540. [CrossRef]

35. Bryliakov, K.P.; Talsi, E.P.; Bochmann, M. ${ }^{1} \mathrm{H}$ and ${ }^{13} \mathrm{C}$ NMR Spectroscopic Study of Titanium(IV) Species Formed by Activation of $\mathrm{Cp}_{2} \mathrm{TiCl}_{2}$ and $\left[\left(\mathrm{Me}_{4} \mathrm{C}_{5}\right) \mathrm{SiMe}_{2} \mathrm{NtBu}\right] \mathrm{TiCl}_{2}$ with Methylaluminoxane (MAO). Organometallics 2004, 23, 149-152. [CrossRef]

36. Talsi, E.P.; Bryliakov, K.P.; Semikolenova, N.V.; Zakharov, V.A.; Ystenes, M.; Rytterc, E. ${ }^{1} \mathrm{H}$ NMR characterization of intermediates formed by the activation of zirconocenes with methylaluminoxane at high $\mathrm{Al} / \mathrm{Zr}$ ratios. Mendeleev Commun. 2003, 13, 46-48. [CrossRef] 
37. Bryliakov, K.P.; Semikolenova, N.V.; Yudaev, D.V.; Ystenes, M.; Rytter, E.; Zakharov, V.A.; Talsi, E.P. ${ }^{1} \mathrm{H}$ and ${ }^{13} \mathrm{C}$ NMR Study of the Intermediates Formed by $(\mathrm{Cp}-\mathrm{R})_{2} \mathrm{ZrCl}_{2}$ Activation with MAO and $\mathrm{AlMe}_{3} /\left[\mathrm{CPh}_{3}\right]\left[\mathrm{B}\left(\mathrm{C}_{6} \mathrm{~F}_{5}\right)_{4}\right]$. Correlation of Spectroscopic and Ethene Polymerization Data. Macromol. Chem. Phys. 2003, 204, 1110-1117. [CrossRef]

38. Bryliakov, K.P.; Semikolenova, N.V.; Yudaev, D.V.; Zakharov, V.A.; Brintzinger, H.H.; Ystenes, M.; Rytter, E.; Talsi, E.P. ${ }^{1} \mathrm{H}-,{ }^{13} \mathrm{C}-\mathrm{NMR}$ and ethylene polymerization studies of zirconocene/MAO catalysts: Effect of the ligand structure on the formation of active intermediates and polymerization kinetics. J. Organomet. Chem. 2003, 683, 92-102. [CrossRef]

39. Babushkin, D.E.; Brintzinger, H.-H. Activation of Dimethyl Zirconocene by Methylaluminoxane (MAO) Size Estimate for Me-MAO- Anions by Pulsed Field-Gradient NMR. J. Am. Chem. Soc. 2002, 124, 12869-12873. [CrossRef] [PubMed]

40. Babushkin, D.E.; Semikolenova, N.V.; Zakharov, V.A.; Talsi, E.P. Mechanism of dimethylzirconocene activation with methylaluminoxane: NMR monitoring of intermediates at high $\mathrm{Al} / \mathrm{Zr}$ ratios. Macromol. Chem. Phys. 2000, 201, 558-567. [CrossRef]

41. Rocchigiani, L.; Busico, V.; Pastore, A.; Macchioni, A. Probing the interactions between all components of the catalytic pool for homogeneous olefin polymerisation by diffusion NMR spectroscopy. Dalton Trans. 2013, 42, 9104-9111. [CrossRef] [PubMed]

42. Ciancaleoni, G.; Fraldi, N.; Budzelaar, P.H.M.; Busico, V.; Macchioni, A. Structure and Dynamics in Solution of Bis(phenoxy-amine)Zirconium Catalysts for Olefin Polymerization. Organometallics 2011, 30, 3096-3105. [CrossRef]

43. Groch, P.; Dziubek, K.; Czaja, K.; Białek, M.; Adamczyk-Tomiak, K.; Rabiej, S.; Dudziec, B. Ethylene/POSS copolymerization behavior of postmetallocene catalysts and copolymer characteristics. J. Polym. Sci. Part A Polym. Chem. 2017, 55, 3918-3934. [CrossRef]

44. Bellamy, L.J. The Infrared Spectra of Complex Molecules; Chapman and Hall: London, UK, 1975; Chapter 20.

45. Anderson, D.R. Analysis of Silicones; Wiley-Interscience: New York, NY, USA, 1974; Chapter 10.

46. Launer, P.J.; Arkles, B. Reprinted from Silicon Compounds: Silanes \& Silicones; Gelest, Inc.: Morrisville, PA, USA, 2013.

47. Fineman, M.; Ross, S.D. Linear method for determining monomer reactivity ratios in copolymerization. J. Polym. Sci. 1950, 5, 259-262. [CrossRef]

48. Bruaseth, I.; Rytter, E. Dual site ethene/1-hexene copolymerization with MAO activated (1,2,4-Me $\left.{ }_{3} \mathrm{Cp}\right)_{2} \mathrm{ZrCl}_{2}$ and $\left(\mathrm{Me}_{5} \mathrm{Cp}\right)_{2} \mathrm{ZrCl}_{2}$ catalysts. Possible transfer of polymer chains between the sites. Macromolecules 2003, 36, 3026-3034. [CrossRef]

49. Kokko, E.; Pietikäinen, P.; Koivunen, J.; Seppälä, J.V. Long-chain-branched polyethene by the copolymerization of ethene and nonconjugated $\alpha, \omega$-dienes. J. Polym. Sci. Part A Polym. Chem. 2001, 39, 3805-3817. [CrossRef]

50. Song, S.; Wu, A.; Yu, Y.; Yang, P.; Fu, Z.; Fan, Z. Nonconjugated diene homopolymerization and copolymerization with ethylene catalyzed by $\alpha$-diimine $\mathrm{Ni}(\mathrm{II})$ complex/Et $\mathrm{A}_{2} \mathrm{AlCl}$. J. Polym. Sci. Part A Polym. Chem. 2017, 55, 1900-1909. [CrossRef]

(C) 2018 by the authors. Licensee MDPI, Basel, Switzerland. This article is an open access article distributed under the terms and conditions of the Creative Commons Attribution (CC BY) license (http:/ / creativecommons.org/licenses/by/4.0/). 